\title{
Probing $\mathrm{Ga}_{\mathrm{i} 1}$ Protein Activation at Single Amino Acid Resolution
}

\author{
Dawei Sun ${ }^{1,2}$, Tilman Flock ${ }^{\# 3}$, Xavier Deupi ${ }^{\# 1,4}$, Shoji Maeda ${ }^{1,6}$, Milos Matkovic $^{1,2}$, Sandro \\ Mendieta $^{1}$, Daniel Mayer ${ }^{1,2}$, Roger Dawson ${ }^{5}$, Gebhard F.X. Schertler ${ }^{1,2}$, M. Madan Babu ${ }^{3}$, \\ and Dmitry B. Veprintsev ${ }^{1,2}$
}

${ }^{1}$ Laboratory of Biomolecular Research, Paul Scherrer Institute, Villigen, Switzerland ${ }^{2}$ Department of Biology, Swiss Federal Institute of Technology Zurich, Zurich, Switzerland ${ }^{3}$ Medical Research Council Laboratory of Molecular Biology, Cambridge, United Kingdom ${ }^{4}$ Condensed Matter Theory Group, Paul Scherrer Institut, Villigen, Switzerland ${ }^{5}$. Hoffmann-La Roche AG, Pharma Research \& Early Development, Discovery Technologies, Basel, Switzerland

\# These authors contributed equally to this work.

\section{Abstract}

We present comprehensive single amino acid resolution maps of the residues stabilising the human $\mathrm{Ga}_{\mathrm{i} 1}$ subunit in nucleotide- and receptor-bound states. We generated these maps by measuring the effects of alanine mutations on the stability of $\mathrm{Ga}_{\mathrm{i} 1}$ and of the rhodopsin- $\mathrm{Ga}_{\mathrm{i} 1}$ complex. We identified stabilization clusters in the GTPase and helical domains responsible for structural integrity and the conformational changes associated with activation. In activation cluster I, helices a 1 and a 5 pack against strands $\beta 1-3$ to stabilize the nucleotide-bound states. In the receptorbound state, these interactions are replaced by interactions between a 5 and strands $\beta 4-6$. Key residues in this cluster are Y320, crucial for the stabilization of the receptor-bound state, and F336, which stabilizes nucleotide-bound states. Destabilization of helix a 1, caused by rearrangement of this activation cluster, leads to the weakening of the inter-domain interface and release of GDP.

\section{Introduction}

G protein coupled receptors (GPCRs) turn extracellular signals into intracellular responses by activating heterotrimeric $\mathrm{G}$ proteins 1-3. Upon binding an activating ligand, receptors catalyse the release of GDP bound to the Ga subunit. Subsequent binding of GTP causes dissociation of the $\mathrm{Ga}$ and $\mathrm{G} \beta \gamma$ subunits from the receptor. A large number of mutagenesis studies proposed the $\mathrm{C}$-terminal helix $\mathrm{a} 5$ of $\mathrm{Ga}$ as a key interaction site for receptor binding and as a conduit for signal transduction 4-9. These data, in combination with crystal structures of individual $\mathrm{G}$ protein subunits and of trimetric $\mathrm{G}$ proteins provided a broad

\footnotetext{
Correspondence should be addressed to D.B.V., dmitry.veprintsev@psi.ch.

6 current address: Department of Molecular and Cellular Physiology, Stanford University, Stanford, USA Author Contributions

DS collected and performed all data analysis. TF helped with analysis and interpretation. SMaeda, SMendieta and DM helped with experiments. XD built the molecular models, and MM helped with the interpretation of the structural effects of mutations. RD, GFXS and MMB contributed to the discussion and writing the manuscript. DS, XD and DBV wrote the manuscript. All authors read and provided their comments on the draft. DS and DBV conceived research and DBV supervised the project.
} 
understanding of the $\mathrm{G}$ protein activation mechanism 2,10-15. More recently, the crystal structure of the $\beta 2$ adrenergic receptor-Gs complex ( $\left.\beta_{2} \mathrm{AR}-\mathrm{Gs}\right) 16$ confirmed that the main site of interaction between the receptor and the $\mathrm{G}$ protein is the $\mathrm{C}$-terminus of helix a 5, and revealed additional contacts between intracellular loop 2 (ICL2) of the receptor and helix $\mathrm{aN}$ of the $\mathrm{Ga}_{\mathrm{s}}$. The largest conformational change in the GTPase domain was a rotation of helix $a 5$ and its displacement towards the receptor, accompanied by rearrangements of the a5- $\beta 6$ interface, the phosphate binding $\beta 1-\mathrm{a} 1$ loop (P-loop) and helix a 1 . This structure also showed the dissociation between the GTPase and helical domains of the G protein, consistent with previous BRET, DEER and single particle electron microscopy data 17-19. Furthermore, analysis of hydrogen-deuterium exchange mass spectrometry data 20 has led to suggest that $\mathrm{G}$ protein activation is also associated with an increased disorder around the $\beta 1$ strand and the nucleotide binding pocket, especially the P-loop and the adjacent $\mathrm{N}$ terminal part of helix a5, while the $\mathrm{C}$-terminus of $\mathrm{Ga}$ was protected upon binding the receptor.

A recent modelling study 21 has suggested that $G$ protein activation is associated with the rearrangement of the interfaces between helices $\alpha 1$ and $\alpha 5$, and between $a 5$ and the loop a5- 36 . Subsequent experimental mutagenesis studies 22 pinpointed residue F336 in helix a 5 of $\mathrm{Ga}_{\mathrm{i} 1}$ as a particularly important for $\mathrm{G}$ protein activation, as its mutation increases the rate of spontaneous GDP release. The proposed mechanism involves F336 acting as a relay, transmitting conformational changes via strands $\beta 2, \beta 3$ and helix $\alpha 1$ to the phosphate binding loop.

These combined data suggest a mechanism that involves binding of the $\mathrm{C}$ terminus of $\mathrm{Ga}$ to the receptor accompanied by the formation of additional interactions between the helix aN and the receptor, and transmission of the allosteric signal via the strand $\beta 1$ or via $\beta 2, \beta 3$ and helix $a 1$ to destabilize the nucleotide binding site. However, the exact details of the molecular mechanism of the activation remain unclear.

Here, we set out to establish a detailed and comprehensive understanding of the G protein activation mechanism at the residue level that consolidates and extends the existing knowledge. To do this, we characterized the influence of each amino acid of $\mathrm{Ga}_{\mathrm{i} 1}$ on the stability of the GDP- and GTP-bound states of $\mathrm{Ga}_{\mathrm{i} 1}$ alone, and of the signaling complex between heterotrimeric $\mathrm{G}_{\mathrm{i}}\left(\mathrm{Ga}_{\mathrm{i} 1} \beta_{1} \gamma_{1}\right)$ and rhodopsin (Rho), a prototypical GPCR. The aggregated analysis of these data allowed us to draw a complete functional map of the $\mathrm{Ga}_{\mathrm{i} 1}$ subunit stability at different stages of its activation cycle that allowed us to propose an activation mechanism at single amino acid resolution.

\section{Results}

We have recently showed that the complex between the heterotrimeric $G_{i}\left(G a_{i 1} \beta_{1} \gamma_{1}\right)$ and rhodopsin (Rho) is more stable than the native Rho- $\mathrm{G}_{\mathrm{t}}$ complex and is suitable for biophysical studies23. In this work we mutated each amino acid of $\mathrm{Ga}_{\mathrm{i} 1}$ to alanine or glycine and quantified 1) the thermal stability of each mutant in the inactive GDP-bound and the active GTP(GTP $\gamma$ S)-bound states (Fig. $1 \&$ 2, Supplementary Fig. S1, Supplementary Table 1, methods); and 2) the efficiency of formation (relative abundance) and relative 
stability of the reconstituted Rho- $\mathrm{G}_{\mathrm{i}}$ protein complex (Fig. 1, Supplementary Fig. S2, S3, S4, Supplementary Table 1, methods).

\section{Interpretation of the changes in stability upon mutation}

Mutation of an amino acid to alanine (or, to glycine, if the original amino acid is alanine) results in the elimination of the side chain, which leads to an alteration of the local structure that changes the stability of a protein or complex. If this mutation has a large effect on protein stability, this suggests that the side chain was involved in many local interactions, indicating a structured environment. Conversely, a small change in stability implies that the side chain is not involved in many local interactions. Thus, if point mutations along a stretch of residues do not affect protein stability, this region is likely to be unstructured.

Importantly, changes in protein stability are sensitive to conformational rearrangements. This is the basis of phi-value analysis, a technique developed by Alan Fersht and colleagues to study the energetic and structural details of protein folding intermediates 24 . Here, we have adapted this method to study conformational changes of $\mathrm{G}_{\mathrm{i}}$ in the GTP-bound and Rho*- $\mathrm{G}_{\mathrm{i}}$ (where Rho* denotes light-activated state of rhodopsin) complex relative to $\mathrm{G}_{\mathrm{i}}$ in the GDP-bound state, which we used as a reference state.

Comparison of the effects of mutations on stability for several conformational states of the protein substantially increases the "interrogating" power of the alanine scanning technique. Importantly, this technique requires a wide coverage of the protein sequence, ideally approaching $100 \%$ of mutated residues. Through the integration of this exhaustive data set, we generated a detailed interpretation of the conformational changes during protein activation, which allowed us to expand, test, or rule out existing hypothesis on the activation mechanism of $\mathrm{G}$ proteins.

These simple considerations formed the basis for interpreting the measured stability changes in structural terms. For instance, we found that many mutations (30-50\%) destabilize both GDP-bound $\mathrm{Ga}_{\mathrm{i} 1}$ and the Rho*-G $\mathrm{G}_{\mathrm{i}}$ complex (Fig. $1 \& 2$, Supplementary Table 1). These residues are located in regions with the same local environment (i.e. conformation) in both states, and are thus important for the stability and integrity of the protein. However, mutations at several positions have different effects on GDP-bound $\mathrm{Ga}_{\mathrm{i} 1}$ and the Rho*- $\mathrm{G}_{\mathrm{i}}$ complex, indicating that they are in regions that undergo conformational changes upon formation of the complex. This way we identified positions that contributed specifically to the stability of $\mathrm{Ga}_{\mathrm{i} 1}$ in each conformation (Fig. 3).

In order to compare and extrapolate our findings to other Ga proteins, throughout this paper we used the common $\mathrm{G}$ protein numbering system (CGN) proposed in Flock et al.25 In this system, the superscript next to the residue number denotes: i) either the GTPase (G) or helical $(\mathrm{H})$ domain, ii) the secondary structure element within each domain (e.g. HN for helix $\mathrm{N}$ or $\mathrm{S} 1$ for beta sheet $\beta 1$ ), and iii) its position within this structural element (e.g. 1), according to a sequence alignment of $973 \mathrm{G}$ protein sequences. For example, L353 ${ }^{\text {G.H5.25 }}$ corresponds to the $\mathrm{L} 353$ in $\mathrm{Ga}_{\mathrm{i} 1}$, GTPase domain, helix 5, and position 25 of the helix 5 in the universal alignment. 


\section{$\mathrm{N}$ - and C-termini become ordered in the $\mathrm{Rho}^{*}-\mathrm{G}_{\mathrm{i}}$ complex}

The N-terminus provided an excellent benchmark to test the capabilities of our method. Mutations at positions $1^{\text {G.HN.8 }}$ to $32^{\text {G.HNS1.3 }}$ had little impact on the stability of $\mathrm{Ga}_{\mathrm{i} 1}$ alone, suggesting that this region was unstructured in the absence of the G $\beta \gamma$ subunit. However, mutations of the residues that form the interface with $G \beta \gamma$ in the $G$ protein trimer (e.g., L5A ${ }^{\text {G.HN.12 }}, \mathrm{S} 16 \mathrm{~A}^{\text {G.HN.40 }}, \mathrm{I}_{19 \mathrm{~A}^{\text {G.HN.43 }}, \mathrm{D} 20 \mathrm{~A}^{\text {G.HN.44 }} \text { and L23A }}{ }^{\text {G.HN.47}}$ ) had a severe impact on the stability of the Rho*- $\mathrm{G}_{\mathrm{i}}$ complex, while mutation of the residues in this region facing the solvent did not have such effect (Fig 1, Supplementary Table 1).

Mutation of R32 ${ }^{\text {G.HNS1.3 }}$ at the base of the N-terminus stabilized the Rho*- $\mathrm{G}_{\mathrm{i}}$ complex, most likely by improving its interactions with intracellular loop 2 (ICL2) of the receptor. This stabilization effect is probably receptor specific and thus may contribute to receptor-G protein specificity. It is also possible that this position is interacting with the helical domain in its most "open" conformation as shown in Fig $1 b$.

Numerous studies have shown that the last eleven residues in the C-terminus of $\mathrm{Ga}$ play a critical role in receptor binding8,9,26,27. Accordingly, most alanine mutations at positions 344 G.H5.16-354 G.H5.26 considerably affected the formation of the Rho*-G ${ }_{i}$ complex (Fig. 1 \& 4). Particularly, substitution of the conserved L $348^{\text {G.H5.20 }}$ and L353 ${ }^{\text {G.H5.25 }}$ and the less conserved G352 $2^{\mathrm{G} . \mathrm{H} 5.24}$ at the end of the C-terminus severely impaired coupling with the receptor without affecting the stability of the nucleotide-bound states. These data agreed with NMR and crystallography studies on a $\mathrm{G}_{\mathrm{t}} \mathrm{C}$-terminal peptide bound to rhodopsin, and with the crystal structure of the $\beta_{2} A R-G_{s}$ complex, which showed that the C-terminus of $\mathrm{Ga}_{\mathrm{s}}$ becomes helical and penetrates into a crevice formed in the cytoplasmic side of the transmembrane bundle upon receptor activation 16,20,28,29. Interestingly, N347 A.H5.19 did not affect the formation and stability of the Rho*- $\mathrm{G}_{\mathrm{i}}$ complex, and D350A ${ }^{\text {G.H5.22 }}$ even slightly stabilized it (Fig. 4a), showing that not all amino acids in the C-terminus have the same effect on receptor binding. Finally, the absence of a destabilizing effect upon mutating positions $344^{\text {G.H5.16-354 }}$ G.H5.26 in the nucleotide bound states strongly suggested that this region was unstructured in the absence of the receptor.

\section{Rearrangement of activation cluster I upon complex formation}

The movement of helix a 5 in the GTPase domain upon formation of the complex 4,16,21 results in significant conformational changes around its base, which is packed against the $\beta$ sheet consisting of strands $\beta 1-\beta 6$, and helix $\alpha 1$. Our data are in agreement with such rearrangements, as shown by the different effect of mutations on the nucleotide-bound state and on the complex. Importantly, our analysis allowed us to focus on the individual contribution to the stability of the different $\mathrm{Ga}_{\mathrm{i} 1}$ states of each amino acid of this entire region. We detected a number of residues with a concerted role, which we termed as activation cluster I (Fig 3 and 5a), formed by several highly conserved hydrophobic residues from $\beta 1-3$ strands, helix $a 1$ and inward-facing residues of helix a5. Alanine substitutions of these residues considerably destabilized the GDP-bound conformation $\left(3-18{ }^{\circ} \mathrm{C}\right)$ and moderately affected the GTP $\gamma \mathrm{S}$-bound state $\left(1-5^{\circ} \mathrm{C}\right)$ (Fig. 5a \& 6a, Supplementary Fig. S5a, Supplementary Table 1). Importantly, mutation of F336 ${ }^{\text {G.H5.8 }}$ (universally conserved in Ga 
subfamilies; see Flock et al25) in helix a 5 is the only substitution that resulted in a complete impairment of $\mathrm{Ga}_{\mathrm{i} 1}$ stability and of its ability to bind nucleotides. F336A $\mathrm{A}^{\mathrm{G} . \mathrm{H} 5.8}$ also caused protein aggregation and a severe impairment in reconstitution of $\mathrm{Ga}_{\mathrm{i} 1}$ with $\mathrm{G} \beta \gamma$ to form the $\mathrm{Ga} \beta \gamma$ heterotrimer (Supplementary Fig. S6). Interestingly, this mutant still formed a relatively stable complex with the receptor. In the structure of the $\beta_{2} A R-G_{s}$ complex, the corresponding phenylalanine moved from the buried hydrophobic core of $\mathrm{Gs}_{\mathrm{a}}$ to contact ICL2 of the receptor16. This suggests that F336 ${ }^{\mathrm{G} . \mathrm{H} 5.8}$ plays a critical role in stabilizing the $\mathrm{Ga}_{\mathrm{i} 1}$ subunit in the nucleotide-bound conformation, consistent with the observation that its mutation increases the rate of spontaneous nucleotide release22. We hypothesized that relocation of F336 ${ }^{\text {G.H5.8 }}$ concomitant with the upward movement and twist of a 5 triggers the reorganization of the cluster I into the receptor-bound state.

Upon binding the receptor, a structural reorganization of cluster I disrupts the interactions that stabilize helix a 1 (Fig. 5a). This is suggested by the fact that mutation of residues I $49^{\text {G.H1.4 }}$, M53 ${ }^{\text {G.H1.8 }}$, and I56 ${ }^{\text {G.H1.11 }}$ in a 1, L38 $8^{\text {G.S1.6 }}$ of $\beta 1$, T329 ${ }^{\text {G.H5.1 }}$ and V332 $2^{\text {G.H5.4 }}$ of $a 5$, which tether helix a 1 in the $\mathrm{Ga}_{11}$-GDP state, severely impaired its stability, but did not affect the stability of Rho*-G $\mathrm{G}_{\mathrm{i}}$ complex (Fig. 6a, Supplementary Table 1). Moreover, mutation of the conserved N331 $1^{\text {G.H5.3 }}$ and V332 $2^{\text {G.H5.4 }}$ in helix a5, which stabilizes the nucleotide-bound state by making connections to the helix a 1 , increased the stability of the complex by $30 \%$ and $20 \%$, respectively. Movement of these residues disrupted contacts between the base of helix a 5 and helix a 1, which would lead to the loss of helicity at the base of helix a 5 observed in the $\beta_{2} A R-G_{s}$ complex 16. This order-to-disorder transition potentially increased the flexibility of the loop $\beta 6$ - $a 5$, which contains the guanine-ringbinding TCAT motif, thus perturbing its interaction with GDP.

The loss of local structural stability associated with an increased disorder in the C-terminal part of helix $a 1$ and the $\mathrm{N}$-terminal part of helix $a 5$ is compensated by the strengthening of their interactions with the $\beta 4, \beta 5$ and $\beta 6$ strands and the relocated helix $a 5$. This is suggested by the fact that mutation of A220 ${ }^{\text {G.S4.1 }}$ of $\beta 4$, S263 ${ }^{\text {G.S5.1 }}$ and $\mathrm{I} 265^{\text {G.S5.3 }}$ of $\beta 5$, Y320 G.S6.2 and H322 G.S6.4 of $\beta 6$, Q333 ${ }^{\text {G.H5.5 }}$, F334 ${ }^{\text {G.H5.6 }}$, V335 ${ }^{\text {G.H5.7 }}$, and V342 ${ }^{\text {G.H5.14 }}$ of a5 dramatically destabilized the Rho*- $\mathrm{G}_{\mathrm{i}}$ complex (20-50\%) without affecting the stability of both nucleotide-bound states. Additionally, many of these mutants showed competent heterotrimer reconstitution, while the efficiency in forming the Rho*- $\mathrm{G}_{\mathrm{i}}$ complex was reduced by $20-80 \%$ (Supplementary Fig. S6). A sequence alignment of human G proteins showed that these residues are highly conserved in the Ga subfamily25. Taken together, this indicates that these residues are not only important for stabilizing the $G$ protein conformation in the receptor-bound state, but also crucial for allosteric regulation of receptor-mediated $\mathrm{G}$ protein activation.

\section{Y320 in activation cluster I as a signal transduction hub}

Mutation of Y320 3.56 .2 in the $\beta 6$ strand, which is a conserved tyrosine or phenylalanine in the Ga subfamily, severely impaired the Rho*-G ${ }_{i}$ complex formation (Fig. 5a \& 6a) while having only a very moderate effect on the nucleotide bound states. Remarkably, Y320A ${ }^{\text {G.S6.2 }}$, L348A ${ }^{\text {G.H5.20 }}$, G352A $\mathrm{A}^{\text {G.H5.24 }}$ and L353A ${ }^{\text {G.H5.25 had a similarly strong impact }}$ on the formation of the complex, but $\mathrm{Y} 320^{\mathrm{G} . S 6.2}$ is the only position that does not interact 
directly with the receptor. Also, Y320A ${ }^{\text {G.S6.2 }}$ showed a well-preserved ability to bind nucleotides and form the heterotrimer (Supplementary Fig. S6). We hypothesized that mutation of $\mathrm{Y} 320^{\mathrm{CGN}}$ prevented the formation of an allosteric activation pathway that propagates the signal for GDP release transmitted from the receptor, making Y320 G.S6.2 a key signal transduction hub in the mechanism of receptor-mediated $\mathrm{G}$ protein activation.

\section{Cluster II is the structural scaffold of GTPase domain}

We identified a second cluster of residues with a common role in the GTPase domain formed by residues in helices $\alpha 3, a 4$ and $a \mathrm{G}$ packed against residues in strands $\beta 4, \beta 5$ and $\beta 6$ (Fig $3 \& 5$ b). While cluster II partially overlapped with cluster I, most mutations here destabilized both receptor- and nucleotide-bound states of $\mathrm{Ga}_{\mathrm{i} 1}$. Most mutations destabilized the GDP-bound state by $3-13{ }^{\circ} \mathrm{C}$, the receptor-bound state by $30-40 \%$, and the GTP $\gamma \mathrm{S}$ bound state by $1-5^{\circ} \mathrm{C}$ (Fig. $5 \mathrm{~b} \& 6 \mathrm{~b}$ ). Residues in cluster II are highly conserved among G proteins, and likely form the structural scaffold of the Ga subunit25. It should be noted that mutation of residues I221 G.S4.2 of $\beta 4$, T32 ${ }^{\text {G.S6.3 }}$, M247 ${ }^{\text {G.H3.6 }}$ and I253 ${ }^{\text {G.H3.12 }}$, I264 ${ }^{\text {G.S5.2, }}$, N311 G.h4s6.2 and I319 ${ }^{\text {G.S6.1 }}$ dramatically destabilized R*-Gi complex without affecting the stability of the GDP-bound state (Fig. 6b, Supplementary Table 1). Mutation of K248G.H3.7 and D251 G.H3.10, which are located in solvent-exposed surface, also showed similar effect. We hypothesized that these residues may form additional stabilizing contacts in the receptorbound conformation, or are involved in direct interactions with the receptor.

\section{Helical domain behaves as a rigid body}

A hallmark of G protein activation by the receptor is the release of GDP accompanied by the separation of the GTPase and helical domains. The helical domain consequently displays dynamic equilibrium between multiple orientations relative to the GTPase domain $16,18,19,30$. We showed that a cluster of mostly hydrophobic residues $\left(63^{\text {H.HA.1 }}-176^{\text {H.HF.6 }}\right.$; stabilization cluster III) of $\mathrm{Ga}_{i 1}$ stabilizes the helical domain (Fig. $3 \&$ 7a, Table. S1). In contrast to the activation and stabilization clusters in the GTPase domain, where most mutants affected both the stability and formation of the Rho*-G $\mathrm{G}_{\mathrm{i}}$ complex, mutations in the stabilization cluster III did not affect the formation of the Rho*-G $\mathrm{G}_{\mathrm{i}}$ complex (Fig. 6c \& 7a). A sequence alignment shows that hydrophobic residues are preferred at these positions in all Ga subtypes (Supplementary File F1). This is consistent with the observation that the helical domain can be expressed independently from the GTPase domain while retaining its ability to activate cGMP phosphodiesterase 31 .

However, there were some exceptions. Mutation of A138 ${ }^{\text {H.HD.5 }}$, L156 ${ }^{\text {H.HE.6 }}$, L159 ${ }^{\text {H.HE.9, }}$ R161 ${ }^{\text {H.HE. } 11}$ and I162 ${ }^{\text {H.HE. } 12}$ destabilized the Rho*-G ${ }$ complex without affecting the stability of GDP- and GTP-bound states (Fig. 6c, 7a, S6, Supplementary Table 1). Also, I78 $\mathrm{A}^{\text {H.HA. } 16}$ reduced complex formation by $20 \%$ and L175A $\mathrm{A}^{\text {H.HF.5 }}$ destabilized GDP-bound state and reduced complex formation. This suggest that subtle internal rearrangements of the AH domain are required to keep its integrity in the $\mathrm{Rho}^{*}-\mathrm{G}_{\mathrm{i}}$ complex. 


\section{Weakening of the inter-domain interface promotes activation}

The inter-domain interface in $\mathrm{Ga}_{\mathrm{i} 1}$ is composed by the N-terminal part of helices $\mathrm{aA}, \mathrm{aF}$, $a 1$ and loop of $a F / a 1$ (Fig. 3). Mutation of the residues in this interface dramatically destabilized the GDP-bound state $\left(5-14{ }^{\circ} \mathrm{C}\right)$, but did not destabilize the Rho*- $\mathrm{G}_{\mathrm{i}}$ complex. In fact, mutations K51A ${ }^{\text {G.H1.6 }}, \mathrm{K} 54 \mathrm{~A}^{\mathrm{G} . \mathrm{H} 1.9}$ and $\mathrm{I} 55 \mathrm{~A}^{\mathrm{G}} \mathrm{H1} 110$ increased the relative stability of Rho*-G $\mathrm{G}_{\mathrm{i}}$ complex by $15-20 \%$. We also observed a similar effect for L175A $\mathrm{A}^{\text {H.HF.5 }}$ and

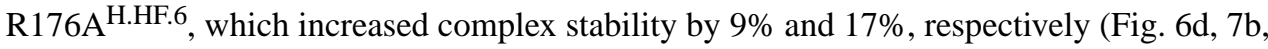
Table. S1). A sequence alignment showed that the residues located in the inter-domain interface of $\mathrm{Ga}_{\mathrm{i} 1}$ are highly conserved in all Ga subfamilies (Supplementary File F1, Flock et al25). Our data suggest that subtle conformational perturbations in the inter-domain interface of GDP-bound state can facilitate the domain separation and the release of GDP, in agreement with previous observations that the helical domain dissociates from the GTPase domain upon binding to the receptor 16-18. The importance of weakening the inter-domain interface for $\mathrm{G}$ protein activation is further supported by the structure of the $\mathrm{Ga}$ subunit from Arabidopsis thaliana (AtGPA1) 32,33. This protein has a structure that is very similar to $\mathrm{Ga}_{\mathrm{i} 1}$ (RMSD of $1.8 \AA$ between backbone atoms). However, due to the absence of classical GPCRs in plants, AtGPA1 exchanges nucleotides by a self-activation mechanism attributed to the marginally stable helical domain, which shows a tendency to dissociate from the GTPases domain and unfold. Comparison between the $\mathrm{Ga}_{\mathrm{i} 1}$-GDP and AtGPA1 structures shows that they contain similar residues at the inter-domain interface, whereas the cross-interface hydrogen bonds in AtGPA1 are weaker compared to those in $\mathrm{Ga}_{\mathrm{i} 1}$-GDP (Supplementary Fig. S7).

\section{Differences between GDP and GTP states}

The GTP $\gamma \mathrm{S}$-bound state of $\mathrm{Ga}_{\mathrm{i} 1}$ was more stable than the GDP-bound state. The apparent melting temperatures were, respectively, $70{ }^{\circ} \mathrm{C}$ and $63{ }^{\circ} \mathrm{C}$ at saturating concentrations of the corresponding nucleotides. In addition, GTP $\gamma \mathrm{S}$ had a much higher affinity for $\mathrm{Ga}_{\mathrm{i} 1}$ compared to GDP, as judged by a steeper concentration dependence of the stabilizing effect (Supplementary Fig. S1). We observed that most mutations destabilized both GDP and GTP $\gamma$ S states, consistent with the relatively minor differences between the GDP- and GTP $\gamma \mathrm{S}$-bound crystallographic structures of $\mathrm{Ga}_{\mathrm{i} 1}$. 34. One interesting observation is that the GTP $\gamma \mathrm{S}$ bound state was on average two-fold less sensitive to mutations (Supplementary Fig. S8), again suggesting that this is a more stable state. Also, several mutations concentrated around the third phosphate group and at the G $\beta \gamma$ interface had a disproportionally large effect on the GTP $\gamma \mathrm{S}$-bound state. This is precisely the area that undergoes conformational changes associated with the activation of the $\mathrm{Ga}$, causing the dissociation of the $\alpha$ and $\beta \gamma$ subunits.

\section{Discussion and Conclusions}

The exhaustive coverage (the entire sequence of the $\mathrm{Ga}_{\mathrm{i} 1}$ subunit) and single amino acid resolution of our mutagenesis analysis, combined with the stability measurements obtained for $\mathrm{Ga}_{\mathrm{i} 1}$ in its GDP-, receptor- and GTP $\gamma \mathrm{S}$-bound states, allowed us to obtain an extremely detailed data set to understand the molecular mechanisms of $\mathrm{G}$ protein activation. Our 
results showed with that the interactions involved in the stabilization of the receptor-bound conformation of $\mathrm{Ga}_{\mathrm{i} 1}$ are broader and more complex that were previously suggested.

First, we identified two clusters of residues that confer stability to the GTPase domain. The activation-cluster I consists of residues in helices a 1 and a 5 packed against residues in strands $\beta 1-3$ in the nucleotide-bound states. In the receptor-bound state, the interactions between $\alpha 5 / \alpha 1$ and $\beta 1-3$ are weakened and compensated by a new set of interactions between $a 5$ and strands $\beta 4-6$. The most prominent examples of residues involved in this rearrangement are Y320 $0^{\text {G.S6.2 }}$ and H322 $2^{\text {G.S6.4 }}$, which are crucial for the stabilization of the receptor-bound state but have no effect on the nucleotide bound state. Conversely, F336 ${ }^{\text {G.H5.8 }}$ is important for the stability of the GDP- and GTP-bound states, but plays little role in the stabilization of the Rho*- $\mathrm{G}_{\mathrm{i}}$ complex. Helix a 1 is likely to become mostly unstructured in the Rho*- $\mathrm{G}_{\mathrm{i}}$ complex, as judged by the absence of significant effect of mutations on complex stability. However, some mutations towards its C-terminal part result in stabilization of the complex. The helix $a 1$ is a recipient of the conformational changes that lead to the destabilization of the inter-domain interface and to nucleotide release, a key step in $\mathrm{G}$ protein activation. Mutations in the inter-domain interface between the GTPase and the helical domains, consisting of $\mathrm{aA}, \mathrm{aF}, \mathrm{a} 1$ and loop of $\mathrm{aF} / \mathrm{a} 1$, dramatically destabilize nucleotide-bound states but do not affect, and some even stabilize, the complex. The abovementioned residues are just some of the most noticeable examples, but we found a network of residues that contribute to the stabilization of these distinct conformational states (Fig. 3, $5 \& 7)$.

In addition to being able to change its conformation, the $\mathrm{G}$ protein also has to maintain its structural integrity and identity during the signaling cycle. Stabilization cluster II includes residues in helices $a 3, a 4$ and $a G$ packed against residues in strands $\beta 4, \beta 5$ and $\beta 6$. The majority of mutations in this cluster affected similarly both states, and we concluded that this cluster provides a steady structural scaffold to the GTPase domain. As this cluster partially overlaps with the activation cluster I, there were several mutations in strands $\beta 4-6$, such as I319 G.S6.1, which preferentially affected the receptor-bound state. A third cluster of residues maintains the structural integrity of the helical domain. Most mutations in this domain resulted in similar effects on the stability of the nucleotide-bound states or the Rho*$\mathrm{G}_{\mathrm{i}}$ complex. Overall, these mutations were less detrimental to the stability than mutations in the GTPase domain. Several mutations, mostly located in helix aH, destabilized the complex without affecting either the GDP- or the GTP-bound state, suggesting that this region undergoes some conformational changes upon receptor binding.

Recently, long-scale molecular dynamics simulations by Dror et al35 suggested that the key events in $\mathrm{G}$ protein activation are structural rearrangements in the nucleotide binding site, especially the repositioning of the $\beta 6$-a 5 loop, caused by the movement of helix a 5 away from the nucleotide binding site, and a concomitant weakening of the inter-domain interface. They also found that the GDP could only dissociate if the helical domain is in the open conformation. Interestingly, the helical domain remains mostly rigid in the simulations. These findings are very complimentary to our results. 
Overall, our data suggest that the most significant event in activation of $\mathrm{Ga}_{\mathrm{i} 1}$ is the destabilization of helix a 1 caused by a rearrangement on the activation cluster I. This leads to a perturbation and weakening of the inter-domain interface, dissociation of the helical domain from the GTPase domain in a rigid body movement, and release of the GDP (Fig. 8). How does the subsequent binding of GTP trigger dissociation of the complex? The answer may be found in the relative stability of the GDP-, GTP- and receptor bound states. The GTP-bound state of $\mathrm{Ga}_{\mathrm{i} 1}$ is thermodynamically the most stable state of the protein, as reflected by the considerably higher thermal stability of the GTP $\gamma \mathrm{S}$-bound state. Due to GTP hydrolysis, the G protein is kinetically trapped in a less stable GDP-bound state. This is a meta-stable state because the nucleotide exchange rate is very low in the absence of the receptor, consistent with proposed role of the helical domain to protect the GDP from exchange with GTP13 readily available in the cytoplasm. As the complex is formed and the nucleotide binding site becomes accessible, the additional stabilization by GTP overcomes the stability of the complex, leads to the stabilization of the helix a 1 , the inter-domain interface and reverts the helix a 5 to its conformation in the nucleotide bound state.

It is still an open question to what extent our findings can be generalized to other GPCR-G protein combinations, and which aspects are specific to the $\mathrm{Ga}_{\mathrm{i} 1}$ or the Rho*-G $\mathrm{G}_{\mathrm{i}}$ complex. However, in Flock et al.25 we show that many of the residues identified here may play similar roles in all $\mathrm{G}$ proteins.

\section{Online Materials and Methods}

\section{1) Alanine scanning mutagenesis}

The alanine scanning expression library of $\mathrm{Ga}_{\mathrm{i} 1}$ was prepared as we have reported before 36. The wild-type (WT) plasmid was constructed by inserting human G protein alphasubunit $\left(\mathrm{Ga}_{\mathrm{i} 1}\right)$ into $\mathrm{pJ} 411$ vector (DNA 2.0$)$ which incorporated a N-terminal 10-histidine tag followed by a TEV cleavage site. The alanine mutants were produced based on the WT plasmid by high-throughput (HTP) alanine mutagenesis as we have reported previously 36. All 354 amino acid residues in Gail were mutated. All non-alanine residues were replaced to alanine and alanine residues were substituted to glycine. The exact protein sequence of the construct is provided in the supplementary note.

\section{2) Preparation of native $\beta \gamma$ subunit $(G \beta \gamma)$}

$\mathrm{G} \beta \gamma$ was separated from endogenous transducin $(\mathrm{Gt})$ as previously described 23 . Briefly, dark-adapted bovine retinas (W L Lawson, USA) were exposed to room light at $4{ }^{\circ} \mathrm{C}$ overnight. The rod outer segment (ROS) membranes were collected by centrifugation in a $25-30 \%$ (w/w) sucrose gradient. After isotonic and hypotonic washes, Gt was dissociated from ROS membrane by adding GTP (Sigma-Aldrich). The collected Gt was filtered through $0.22 \mu \mathrm{m}$ membrane (Millipore Corp) and dialyzed against the dialysis buffer $(10 \mathrm{mM}$ Tris- $\mathrm{HCl}$, pH 7.4, $2 \mathrm{mM} \mathrm{MgCl} 2,1 \mathrm{mM}$ DTT,) containing 50\% glycerol. G $\beta \gamma$ was further separated from the Gat on a Blue-Sepharose column (GE Healthcare) by a linear salt gradient $(0-500 \mathrm{mM} \mathrm{NaCl})$ in the dialysis buffer supplemented with $30 \%$ glycerol. The $\mathrm{G} \beta \gamma$ was concentrated to $1-5 \mathrm{mg} / \mathrm{ml}$ and stored at $-80{ }^{\circ} \mathrm{C}$. 


\section{3) Preparation of bovine rhodopsin}

Bovine rhodopsin was extracted from dark-adapted ROS membranes which were prepared according to Okada's method 37. The dark-adapted ROS membranes were solubilized in

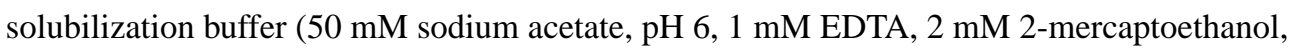
$3 \mathrm{mM} \mathrm{CaCl}_{2}, 3 \mathrm{mM} \mathrm{MgCl}, 3 \mathrm{mM} \mathrm{MnCl}_{2}, 100 \mathrm{mM} \mathrm{NaCl}$ ) supplemented with $80 \mathrm{mM}$ (4.1\%) $\beta$-dodecyl-D-n-maltoside (DDM) at $4{ }^{\circ} \mathrm{C}$ overnight. After centrifugation at 30,000 $\mathrm{rpm}$ in a Ti70 rotor, the supernatant was diluted with solubilization buffer to a concentration of DDM as $0.4 \%$. The diluted sample was loaded to a column packed with ConA Sepharose resin (GE Healthcare) which was equilibrated with washing buffer (solubilization buffer supplemented with $0.02 \%$ DDM). After extensive washing, bovine rhodopsin was eluted with solubilization buffer supplemented with $0.02 \%$ DDM and $0.2 \mathrm{M} \mathrm{a-D-}$

methylmannoside. The eluted bovine rhodopsin was concentrated to $1-4 \mathrm{mg} / \mathrm{ml}$ and stored at $-80{ }^{\circ} \mathrm{C}$.

\section{4) High throughput (HTP) culturing and purification of $\mathrm{Ga}_{\mathrm{i} 1}$ alanine mutants}

The recombinant Gai1 alanine mutants were expressed in BL21 (DE3) competent cells. The cultures were grown at $37^{\circ} \mathrm{C}$ in TB media (GERBU Biotechnik GmbH) by using 24 well plates (mutant/well) (Whatman UniFilter Microplates, GE Healthcare). The culture volume was $5 \mathrm{ml} /$ well. When the OD600 reached 0.6, cells were induced with $0.5 \mathrm{mM}$ IPTG and continued to grow for 20 hours at $20^{\circ} \mathrm{C}$. The cell were harvested by centrifugation resuspended in the binding buffer ( $25 \mathrm{mM}$ Tris- $\mathrm{HCl}, \mathrm{pH} 7.4,500 \mathrm{mM} \mathrm{NaCl}, 10 \%$ glycerol, $50 \mathrm{mM}$ imidazole, $5 \mathrm{mM}$ 2-mercaptoethanol) and transferred to a 96 deep-well plate (Thermo Scientific). The re-suspended cells were disrupted by sonication for $1 \mathrm{~min}$ using a SONICS VCX-600 sonicator equipped with an 8-pin probe. After clarifying cell lysates by centrifugation, the supernatants were loaded to a 96 deep-well filter plate (one mutant per well) pre-loaded with $500 \mu \mathrm{l}$ cobalt chelating resin (GE Healthcare) and equilibrated with binding buffer. After extensive washing with binding buffer, the recombinant Gai1 alanine mutants were eluted with elution buffer ( $25 \mathrm{mM}$ Tris- $\mathrm{HCl}$, pH 7.4, $500 \mathrm{mM} \mathrm{NaCl}, 10 \%$ glycerol, $500 \mathrm{mM}$ imidazole, $5 \mathrm{mM}$ 2-mercaptoethanol). The eluted proteins were dialyzed against $25 \mathrm{mM}$ Hepes, $\mathrm{pH}$ 7.4, $100 \mathrm{mM} \mathrm{NaCl}$ and $2 \mathrm{mM}$ DTT using Slide-A-Lyzer MINI Dialysis Device (Thermo Scientific). Among of 354 alanine mutants, the purified R142A ${ }^{\text {H.HD.9 }}$, Y230A ${ }^{\text {G.s4h3.4 }}$ K270A ${ }^{\text {G.s5hg.1 }}$ and D272A ${ }^{\text {G.HG.2 }}$ were severely aggregated and could not be used in the further assays. The flowchart of HTP purification is shown in Supplementary Fig. S1.

\section{5) Characterization of the effect of $\mathrm{Ga}_{\mathrm{i} 1}$ alanine mutants on the receptor-bound state by a HTP assay}

In each round, WT $\mathrm{Ga}_{\mathrm{i} 1}$ was always prepared in parallel with the $\mathrm{Ga}_{\mathrm{i} 1}$ alanine mutants $\left[\mathrm{Ga}_{\mathrm{i} 1}(\mathrm{Ala})\right]$ to form rhodopsin- $\mathrm{G}_{\mathrm{i}}$ protein complex $\left[\mathrm{Rho}{ }^{*}-\mathrm{G}_{\mathrm{i}}(\mathrm{WT})\right]$ as the reference control. The recombinant $\mathrm{Ga}_{\mathrm{i} 1}$ alanine mutants $(12.5 \mu \mathrm{M})$ from HTP purification and the native $\mathrm{G} \beta \gamma_{\mathrm{t}}(10 \mu \mathrm{M})$ were reconstituted to form heterotrimer $\left(\mathrm{G}_{\mathrm{i}}\right)$ by incubation in a 96-well PCR plate (one mutant per well) (Eppendorf) on ice for $2 \mathrm{~h}$. Under the dim-red light in the dark room, purified rhodopsin $(18 \mu \mathrm{M})$ was added and mixed with $\mathrm{G}_{\mathrm{i}}$ in ice-cold assay buffer (25 mM Hepes, pH 7.4, $100 \mathrm{mM} \mathrm{NaCl}, 2 \mathrm{mM}$ DTT, 0.02\% DDM, 1 mM MgCl $2,0.16$ unit $/ \mathrm{ml}$ 
apyrase). After irradiation with orange light (>495 nm) on ice for $10 \mathrm{~min}$, the tetramer complex Rho*-G $\mathrm{G}_{\mathrm{i}}$ (Ala) was formed by coupling the activated rhodopsin with $\mathrm{G}_{\mathrm{i}}$ and the formed Rho*- $\mathrm{G}_{\mathrm{i}}(\mathrm{Ala})$ complex was further incubated in the dark at $4{ }^{\circ} \mathrm{C}$ overnight. The reaction volume was $50 \mu \mathrm{l}$ for each alanine mutant. $20 \mu \mathrm{l}$ of each $\mathrm{Rho}^{*}-\mathrm{G}_{\mathrm{i}}$ (Ala) complex was transferred to another 96-well PCR plate and heated for $30 \mathrm{~min}$ in a PCR machine (Eppendorf Mastercycler Gradient) at $36.3^{\circ} \mathrm{C}$. After centrifugation at $3000 \mathrm{rpm}$ for $10 \mathrm{~min}$ at $4{ }^{\circ} \mathrm{C}, 14 \mu \mathrm{l}$ of formed Rho*-G $\mathrm{G}_{\mathrm{i}}$ (Ala) complex $\left(4^{\circ} \mathrm{C}\right)$ and $14 \mu \mathrm{l}$ of heated Rho*-G $\mathrm{G}_{\mathrm{i}}$ (Ala) complex $\left(36.3^{\circ} \mathrm{C}\right)$ were mixed with NativePAGE Sample Buffer (4x) (Invitrogen) and NativePAGE 5\% G-250 Sample Additive (Invitrogen), respectively. The mixtures were loaded onto 4-16\% NativePAGE Bis-Tris- $\mathrm{HCl}$ Gels (Invitrogen) and gel electrophoresis was performed in a $4^{\circ} \mathrm{C}$ cold room according to the manufacturer's protocol (Invitrogen). Protein markers were used with NativeMark Unstained Protein Standard (Invitrogen). The gel bands of Rho*-G $\mathrm{G}_{\mathrm{i}}$ complex were integrated and quantified using the ImageJ software. The complex formation efficiency (CF) (\%) was obtained from the normalization of integrated density of Rho*-G $\mathrm{G}_{\mathrm{i}}$ complex band $\left[\mathrm{ID}_{\mathrm{C}}\left(\right.\right.$ Ala or WT), $4{ }^{\circ} \mathrm{C}$ ] with integrated density of Rho*-G $\mathrm{G}_{\mathrm{i}}(\mathrm{WT})$ complex band [IDC(WT), $4{ }^{\circ} \mathrm{C}$ ]. The complex stability (CS) (\%) was defined as the normalization of integrated density of $\mathrm{Rho}^{*}-\mathrm{G}_{\mathrm{i}}$ complex band [ID $\mathrm{C}\left(\mathrm{Ala}\right.$ or WT), $36.3{ }^{\circ} \mathrm{C}$ ] with integrated density of Rho*- $\mathrm{G}_{\mathrm{i}}(\mathrm{WT})$ complex band [ID $\mathrm{C}\left(\right.$ Ala or WT), $4^{\circ} \mathrm{C}$ ].

$$
\begin{gathered}
\mathrm{CF}(\mathrm{Ala})=\frac{\mathrm{ID}_{\mathrm{C}}\left(\mathrm{Ala}, 4^{\circ} \mathrm{C}\right)}{\mathrm{ID}_{\mathrm{C}}\left(\mathrm{WT}, 4^{\circ} \mathrm{C}\right)} \times 100 \% \\
\mathrm{CS}(\mathrm{WT})=\frac{\mathrm{ID}_{\mathrm{C}}\left(\mathrm{WT}, 36.3^{\circ} \mathrm{C}\right)}{\mathrm{ID}_{\mathrm{C}}\left(\mathrm{WT}, 4^{\circ} \mathrm{C}\right)} \times 100 \% \\
\mathrm{CS}(\mathrm{Ala})=\frac{\mathrm{ID}_{\mathrm{C}}\left(\mathrm{Ala}, 36.3^{\circ} \mathrm{C}\right)}{\mathrm{ID}_{\mathrm{C}}\left(\mathrm{Ala}, 4^{\circ} \mathrm{C}\right)} \times 100 \%
\end{gathered}
$$

The $\Delta \mathrm{CF}(\%)$ and $\Delta \mathrm{CS}(\%)$ were defined as:

$$
\begin{gathered}
\Delta \mathrm{CF}=\mathrm{CF}(\text { Ala })-\mathrm{CF}(\mathrm{WT}) \\
\Delta \mathrm{CS}=\mathrm{CS}(\text { Ala })-\mathrm{CS}(\mathrm{WT})
\end{gathered}
$$

The distribution and summary of $\Delta \mathrm{CF}$ efficiency and $\Delta \mathrm{CS}$ of each Gai1 alanine mutant are listed in Fig. 2 and Supplementary Table 1. The flowchart diagram of HTP assay is shown in Supplementary Fig. S2.

\section{6) HTP measurements of thermal stability Gai1 alanine mutants by differential scanning fluorimetry (DSF)}

The thermostability of each $\mathrm{Ga}_{\mathrm{i} 1}$ alanine mutant in the nucleotide-bound states was measured by HTP differential scanning fluorimetry (DSF). The samples were prepared on ice. $10 \mu \mathrm{l}$ of recombinant $\mathrm{Ga}_{\mathrm{i} 1}$ alanine mutant stocks $(0.7 \mu \mathrm{g} / \mu \mathrm{l})$ were dispensed into a 96well PCR plate (one mutant per well) (Eppendorf) and mixed with $100 \mu$ ice-cold assay buffer (25mM Hepes, pH 7.4, 100mM NaCl, 2mM DTT) containing 5× SYPRO-orange (Invitrogen) and nucleotides (1 mM GDP or $100 \mu \mathrm{M}$ GTP $\gamma \mathrm{S}$ ). After mixing, $110 \mu \mathrm{l}$ reaction mixture of each alanine mutant was divided into $0.2 \mathrm{ml}$ PCR tubes (Qiagen) as three samples of $35 \mu \mathrm{l}$. The DSF experiments were performed with Rotor GeneQ (Qiagen) by ramping from $25^{\circ} \mathrm{C}$ to $95^{\circ} \mathrm{C}$ at a rate of $3{ }^{\circ} \mathrm{C} / \mathrm{min}$. The melting temperature $\left(T_{\mathrm{m}}\right)$ was defined as the 
inflection point of the melting curve as analyzed by the Rotor Gene Q Series Software. The $T_{\mathrm{m}}$ value of each $\mathrm{Ga}_{\mathrm{i} 1}$ alanine mutant [ $T_{\mathrm{m}}$ (Ala)] upon addition of the nucleotides was averaged from three individual experiments.

The $\Delta T_{\mathrm{m}}$ value was defined as:

$$
\Delta T_{\mathrm{m}}=T_{\mathrm{m}}(\text { Ala })-T_{\mathrm{m}}(\mathrm{WT})
$$

In each round, WT $\mathrm{Ga}_{\mathrm{i} 1}$ was always prepared in parallel with $\mathrm{Ga}_{\mathrm{i} 1}$ alanine mutants as a reference control.

In addition, the thermal shift of $\mathrm{WT} \mathrm{Ga}_{\mathrm{i} 1}$ in titration with GDP and GTP $\gamma \mathrm{S}$ were also performed with HTP DSF.

\section{7) Analysis of heterotrimer formation by fluorescence assisted size exclusion chromatography (FSEC)}

The recombinant $\mathrm{Ga}_{\mathrm{i} 1}$ alanine mutants $(6 \mu \mathrm{M})$ and $\mathrm{G} \beta \gamma_{\mathrm{t}}(2 \mu \mathrm{M})$ were reconstituted to form heterotrimer $\left(\mathrm{G}_{\mathrm{i}}\right)$ in $100 \mu \mathrm{l}$ running buffer $(25 \mathrm{mM}$ Hepes, $\mathrm{pH} 7.4,100 \mathrm{mM} \mathrm{NaCl})$ overnight on ice. $80 \mu \mathrm{l}$ of reconstituted $\mathrm{G}_{\mathrm{i}}$ was injected to Superdex 200 packed in a Tricorn 10/200 column (GE Healthcare) equilibrated with the running buffer. The elution profile was monitored by protein-intrinsic fluorescence with $\lambda$ ex: $280 \mathrm{~nm}$ and $\lambda \mathrm{em}: 340 \mathrm{~nm}$ at a flow rate of $1 \mathrm{ml} / \mathrm{min}$. The retention time of the reconstituted $G_{i}$ was integrated with UNICORN 5.2 software (GE Healthcare).

\section{8) Modelling of the rhodopsin/Gi complex}

Homology modelling of $\mathrm{Ga}_{\mathrm{i} 1}$-The sequences of $\mathrm{Ga}_{\mathrm{i} 1}$ and $\mathrm{Ga}_{\mathrm{s}}$ were aligned using Clustal Omega 38. This initial alignment was manually refined using Chimera 39 to adjust some of the gaps in the loop regions. Using this alignment, $\mathrm{Ga}_{\mathrm{i} 1}$ was modelled with Modeller 40 using the structure of Gs bound to the beta 2 adrenergic receptor 16 as a template. Residues missing in the template were refined using the loop optimization method in Modeller. All models were subjected to 300 iterations of variable target function method optimization and thorough molecular dynamics and simulated annealing optimization and scored using the discrete optimized protein energy potential. The 20 best-scoring models were analyzed visually, and a suitable model (in terms of low score and structure of the loops) was selected.

Homology modelling of active rhodopsin-The sequences of bovine rhodopsin and the human beta 2 adrenergic receptor were aligned using Clustal Omega 38. This initial alignment was manually refined using Chimera 39 to adjust some of the gaps in the loop regions. Using this alignment, rhodopsin was modelled with Modeller 40 using the structure of the beta 2 adrenergic receptor bound to Gs 16 as a template. Residues missing in the template were refined using the loop optimization method in Modeller. All models were subjected to 300 iterations of variable target function method optimization and thorough molecular dynamics and simulated annealing optimization and scored using the discrete 
optimized protein energy potential. The 20 best-scoring models were analyzed visually, and a suitable model (in terms of low score and structure of the loops) was selected.

Modelling of the rhodopsin - Gi complex-The models of $\mathrm{Ga}_{\mathrm{i} 1}$ and rhodopsin were superimposed to the structures of $\mathrm{Ga}_{\mathrm{s}}$ and the beta 2 adrenergic receptor 16, keeping the $\mathrm{G}$ beta and gamma subunits. In addition to the crystallographic waters resolved in the structure of rhodopsin, we added additional ordered water molecules, as observed in the highresolution structure of the adenosine A2A receptor 41. Cysteines 322 and 323 were palmitoylated. Glu, Asp, Arg and Lys residues were set as charged, except Glu122(3.37) and Asp83(2.50) 42. Topology and parameter definitions for palmitoyl-cysteine and retinal bound via protonated Schiff-base link to lysine 43,44 were obtained from the parameter/ topology repository of NAMD 45 . The complex was embedded in a solvated and preequilibrated lipid bilayer consisting of 360 molecules of 1-palmitoyl-2-oleoyl-sn-glycerol-3phosphatidylcholine (POPC) and approx. 50.000 water molecules. Sodium and chloride ions were added to a concentration of $0.15 \mathrm{M} \mathrm{NaCl}$, and then additional ions were added to achieve charge neutrality. The system measured roughly $120 \times 120 \times 160 \AA^{\wedge} 3$, with a total of approximately $215^{\prime} 000$ atoms. This system was equilibrated as follows: first a short $(0.5$ ns) simulation was performed in which only the lipid tails were allowed to move, in order to induce the appropriate disorder of a fluid-like bilayer. Then, the geometry of the entire system was optimized by 1000 steps of energy minimization, followed by two equilibration steps with the protein constrained ( $0.5 \mathrm{~ns})$ and without constraints ( $0.5 \mathrm{~ns})$. In order to equilibrate the complex, the system was subjected to $20 \mathrm{~ns}$ of unrestrained molecular dynamics. Simulations were carried out using NAMD 2.845 with the CHARMM27 allhydrogen force field 46 at constant pressure ( $1 \mathrm{~atm})$, and using a time step of $2 \mathrm{fs}$.

\section{Supplementary Material}

Refer to Web version on PubMed Central for supplementary material.

\section{Acknowledgements}

We thank F. Heydenreich, V. Korkhov, R. Kammerer and C. Piscitelli for the critical reading of the manuscript, and V. Panneels and R. Jaussi for technical support. S. Maeda was supported by the Roche postdoctoral fellowship RPF113. T.F. is Boehringer Ingelheim Fonds PhD fellow. D. M. and S. Mendieta were supported by the Paul Scherrer Institute internship program. This work was supported by Swiss National Science Foundation grants Sinergia 141898 (D.B.V., G.F.X.S.), 133810 31-135754 (D.B.V.), 31-153145 (G.F.X.S.), 31003A-146520 (X.D.), National Centre of Competence in Research (NCCR) Structural Biology, NCCR Molecular Systems Engineering, European Cooperation in Science and Technology Action CM1207 GLISTEN: GPCR-Ligand Interactions, Structures, and Transmembrane Signalling: a European Research Network (X.D. and G.F.X.S.), the Marie Curie Initial Training Network NanoMem (D.B.V., G.F.X.S.), the Medical Research Council (MC_U105185859; M.M.B., T.F.) and the. M.M.B. is a Lister Institute Research Prize Fellow. Molecular dynamics simulations were run at the Swiss National Supercomputing Centre (CSCS).

\section{References}

1. Gilman AG. G proteins: transducers of receptor-generated signals. Annu Rev Biochem. 1987; 56:615-49. [PubMed: 3113327]

2. Wall MA, et al. The structure of the G protein heterotrimer Gi alpha 1 beta 1 gamma 2. Cell. 1995; 83:1047-58. [PubMed: 8521505]

3. Sprang SR. G proteins, effectors and GAPs: structure and mechanism. Curr Opin Struct Biol. 1997; 7:849-56. [PubMed: 9434906] 
4. Oldham WM, Van Eps N, Preininger AM, Hubbell WL, Hamm HE. Mechanism of the receptorcatalyzed activation of heterotrimeric $G$ proteins. Nature structural \& molecular biology. 2006; 13:772-7.

5. Oldham WM, Hamm HE. Heterotrimeric G protein activation by G-protein-coupled receptors. Nat Rev Mol Cell Biol. 2007

6. Marin EP, Krishna AG, Sakmar TP. Rapid activation of transducin by mutations distant from the nucleotide-binding site: evidence for a mechanistic model of receptor-catalyzed nucleotide exchange by G proteins. The Journal of biological chemistry. 2001; 276:27400-5. [PubMed: 11356823]

7. Marin EP, Krishna AG, Sakmar TP. Disruption of the alpha5 helix of transducin impairs rhodopsincatalyzed nucleotide exchange. Biochemistry. 2002; 41:6988-94. [PubMed: 12033931]

8. Garcia PD, Onrust R, Bell SM, Sakmar TP, Bourne HR. Transducin-alpha C-terminal mutations prevent activation by rhodopsin: a new assay using recombinant proteins expressed in cultured cells. The EMBO journal. 1995; 14:4460-9. [PubMed: 7556089]

9. Onrust R, et al. Receptor and betagamma binding sites in the alpha subunit of the retinal G protein transducin. Science. 1997; 275:381-4. [PubMed: 8994033]

10. Coleman DE, et al. Structures of active conformations of Gi alpha 1 and the mechanism of GTP hydrolysis. Science. 1994; 265:1405-12. [PubMed: 8073283]

11. Mixon MB, et al. Tertiary and quaternary structural changes in Gi alpha 1 induced by GTP hydrolysis. Science. 1995; 270:954-60. [PubMed: 7481799]

12. Chen Z, Singer WD, Danesh SM, Sternweis PC, Sprang SR. Recognition of the activated states of Galpha13 by the rgRGS domain of PDZRhoGEF. Structure. 2008; 16:1532-43. [PubMed: 18940608]

13. Noel JP, Hamm HE, Sigler PB. The 2.2 A crystal structure of transducin-alpha complexed with GTP gamma S. Nature. 1993; 366:654-63. [PubMed: 8259210]

14. Lambright DG, Noel JP, Hamm HE, Sigler PB. Structural determinants for activation of the alphasubunit of a heterotrimeric G protein. Nature. 1994; 369:621-8. [PubMed: 8208289]

15. Lambright DG, et al. The 2.0 A crystal structure of a heterotrimeric G protein. Nature. 1996; 379:311-9. [PubMed: 8552184]

16. Rasmussen SG, et al. Crystal structure of the beta2 adrenergic receptor-Gs protein complex. Nature. 2011; 477:549-55. [PubMed: 21772288]

17. Van Eps $\mathrm{N}$, et al. Interaction of a $\mathrm{G}$ protein with an activated receptor opens the interdomain interface in the alpha subunit. Proc Natl Acad Sci U S A. 2011

18. Westfield GH, et al. Structural flexibility of the G alpha s alpha-helical domain in the beta2adrenoceptor Gs complex. Proc Natl Acad Sci U S A. 2011; 108:16086-91. [PubMed: 21914848]

19. Gales $\mathrm{C}$, et al. Probing the activation-promoted structural rearrangements in preassembled receptor-G protein complexes. Nature structural \& molecular biology. 2006; 13:778-86.

20. Chung KY, et al. Conformational changes in the $\mathrm{G}$ protein $\mathrm{Gs}$ induced by the beta 2 adrenergic receptor. Nature. 2011; 477:611-5. [PubMed: 21956331]

21. Alexander NS, et al. Energetic analysis of the rhodopsin-G-protein complex links the alpha5 helix to GDP release. Nature structural \& molecular biology. 2014; 21:56-63.

22. Kaya AI, et al. A conserved phenylalanine as a relay between the alpha5 helix and the GDP binding region of heterotrimeric Gi protein alpha subunit. The Journal of biological chemistry. 2014; 289:24475-87. [PubMed: 25037222]

23. Maeda S, et al. Crystallization scale preparation of a stable GPCR signaling complex between constitutively active rhodopsin and G-protein. PLoS ONE. 2014; 9:e98714. [PubMed: 24979345]

24. Matouschek A, Kellis JT Jr, Serrano L, Fersht AR. Mapping the transition state and pathway of protein folding by protein engineering. Nature. 1989; 340:122-6. [PubMed: 2739734]

25. Flock T, et al. Universal allosteric mechanism for Galpha activation by GPCRs. Nature. 2015

26. Hamm HE, et al. Site of $\mathrm{G}$ protein binding to rhodopsin mapped with synthetic peptides from the alpha subunit. Science. 1988; 241:832-5. [PubMed: 3136547]

27. Osawa S, Weiss ER. The effect of carboxyl-terminal mutagenesis of Gt alpha on rhodopsin and guanine nucleotide binding. J Biol Chem. 1995; 270:31052-8. [PubMed: 8537363] 
28. Standfuss J, et al. The structural basis of agonist-induced activation in constitutively active rhodopsin. Nature. 2011; 471:656-60. [PubMed: 21389983]

29. Dratz EA, et al. NMR structure of a receptor-bound G-protein peptide. Nature. 1993; 363:276-81. [PubMed: 8487866]

30. Van Eps N, et al. Interaction of a G protein with an activated receptor opens the interdomain interface in the alpha subunit. Proc Natl Acad Sci U S A. 2011; 108:9420-4. [PubMed: 21606326]

31. Liu W, Northup JK. The helical domain of a G protein alpha subunit is a regulator of its effector. Proceedings of the National Academy of Sciences of the United States of America. 1998; 95:12878-83. [PubMed: 9789008]

32. Jones JC, et al. The crystal structure of a self-activating $\mathrm{G}$ protein alpha subunit reveals its distinct mechanism of signal initiation. Sci Signal. 2011; 4:ra8. [PubMed: 21304159]

33. Urano D, Chen JG, Botella JR, Jones AM. Heterotrimeric G protein signalling in the plant kingdom. Open Biol. 2013; 3:120186. [PubMed: 23536550]

34. Raw AS, Coleman DE, Gilman AG, Sprang SR. Structural and biochemical characterization of the GTPgammaS-, GDP.Pi-, and GDP-bound forms of a GTPase-deficient Gly42 --> Val mutant of Gialpha1. Biochemistry. 1997; 36:15660-9. [PubMed: 9398294]

35. Dror RO, et al. SIGNAL TRANSDUCTION. Structural basis for nucleotide exchange in heterotrimeric G proteins. Science. 2015; 348:1361-5. [PubMed: 26089515]

36. Sun D, et al. AAscan, PCRdesign and MutantChecker: a suite of programs for primer design and sequence analysis for high-throughput scanning mutagenesis. PLoS ONE. 2013; 8:e78878. [PubMed: 24205336]

37. Iwata, S. Methods and results in crystallization of membrane proteins. International University Line; La Jolla, CA: 2003.

38. Sievers F, et al. Fast, scalable generation of high-quality protein multiple sequence alignments using Clustal Omega. Mol Syst Biol. 2011; 7:539. [PubMed: 21988835]

39. Pettersen EF, et al. UCSF Chimera--a visualization system for exploratory research and analysis. J Comput Chem. 2004; 25:1605-12. [PubMed: 15264254]

40. Webb, B.; Sali, A. Comparative Protein Structure Modeling Using MODELLER. Current Protocols in Bioinformatics. John Wiley \& Sons, Inc.; 2002.

41. Liu W, et al. Structural basis for allosteric regulation of GPCRs by sodium ions. Science. 2012; 337:232-6. [PubMed: 22798613]

42. Mahalingam M, Martinez-Mayorga K, Brown MF, Vogel R. Two protonation switches control rhodopsin activation in membranes. Proc Natl Acad Sci U S A. 2008; 105:17795-800. [PubMed: 18997017]

43. Tajkhorshid E, Baudry J, Schulten K, Suhai S. Molecular dynamics study of the nature and origin of retinal's twisted structure in bacteriorhodopsin. Biophys J. 2000; 78:683-93. [PubMed: 10653781]

44. Nina M, Roux B, Smith JC. Functional interactions in bacteriorhodopsin: a theoretical analysis of retinal hydrogen bonding with water. Biophys J. 1995; 68:25-39. [PubMed: 7711248]

45. Phillips JC, et al. Scalable molecular dynamics with NAMD. J Comput Chem. 2005; 26:1781-802. [PubMed: 16222654]

46. MacKerell AD, et al. All-atom empirical potential for molecular modeling and dynamics studies of proteins. J Phys Chem B. 1998; 102:3586-616. [PubMed: 24889800] 
a) $\quad \mathrm{G}_{\mathrm{i1}}-\mathrm{GDP}$
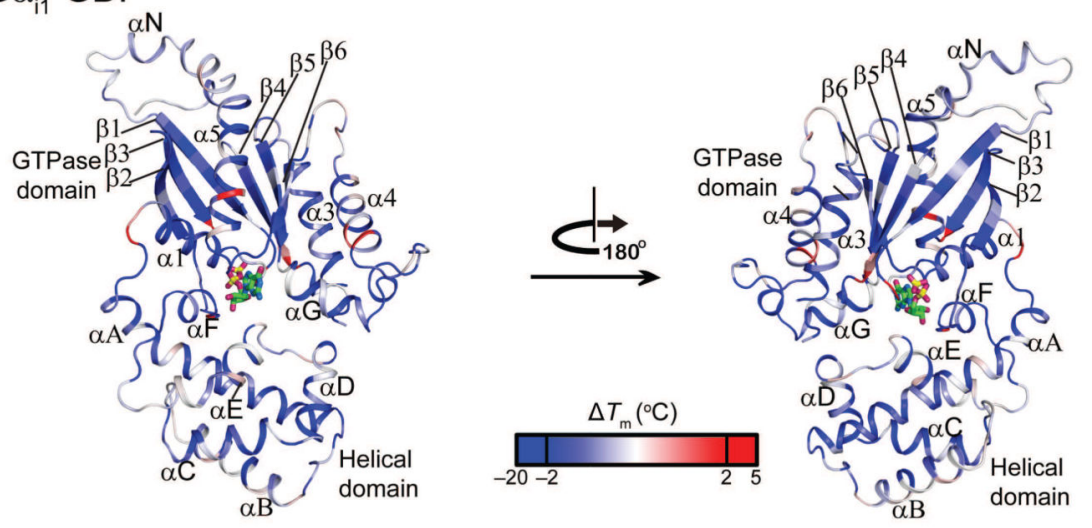

b) $\mathrm{Rho}^{*}-\mathrm{G}_{\mathrm{i}}$

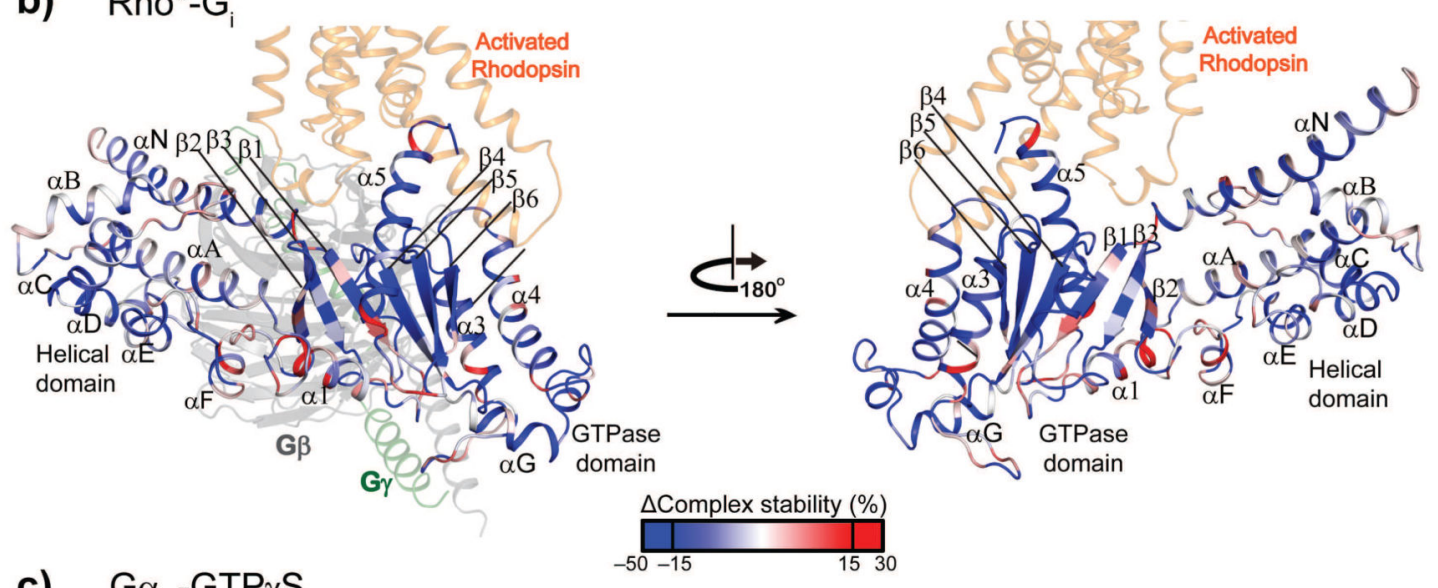

c) $\quad \alpha_{i 1}-G T P \gamma S$
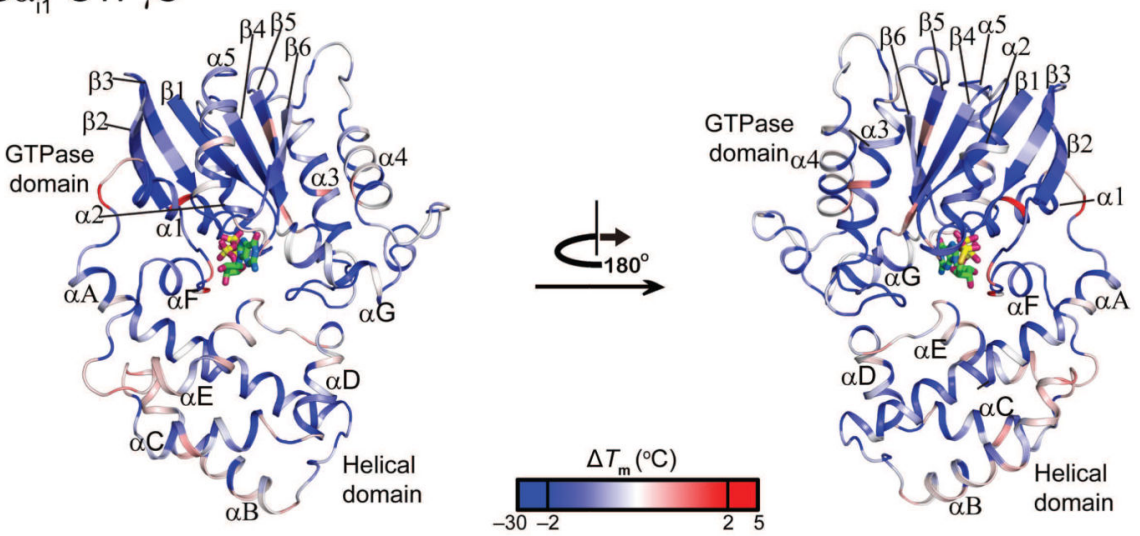

Figure 1. Stability effects of $\mathrm{Ga}_{\mathrm{i} 1}$ alanine mutants on the nucleotide-bound and receptor-bound states.

a-c, Effects of alanine substitutions in $\mathrm{Ga}_{\mathrm{i} 1}$ on stability of the (a) GDP-, (b) receptor- and (c) GTP $\gamma \mathrm{S}$-bound states. In the GDP- (a)and GTP $\gamma \mathrm{S}$-bound (b) states, the $\Delta T_{\mathrm{m}}$ values for each single alanine mutant are mapped onto the crystal structure of GDP-bound $\mathrm{Ga}_{\mathrm{i} 1}(\mathrm{PDB}$ $1 \mathrm{GDD} 11$ ) and $\mathrm{GTP} \gamma \mathrm{S}$-bound $\mathrm{Ga}_{\mathrm{i} 1}$ (PDB 1GIA10), as a spectrum ranging from blue over white to red. In the receptor-bound state (b), the change in the complex stability ( $\Delta$ complex stability) is mapped onto the homology model of Rho*- $\mathrm{G}_{\mathrm{i}}$ complex (see supplementary 
methods) as spectrum ranging from blue over white to red. Rhodopsin is shown in orange. $\beta$ and $\gamma$ subunits are displayed in grey and forest green, respectively. GDP and GTP $\gamma \mathrm{S}$ are shown as sticks. The view of GTPase domain of $\mathrm{Ga}_{\mathrm{i} 1}$ in the complex-bound state is the same as in the GDP- and GTP-bound state, while the helical domain is significantly displaced relative to the GTPase domain in the receptor-bound state. 
a)

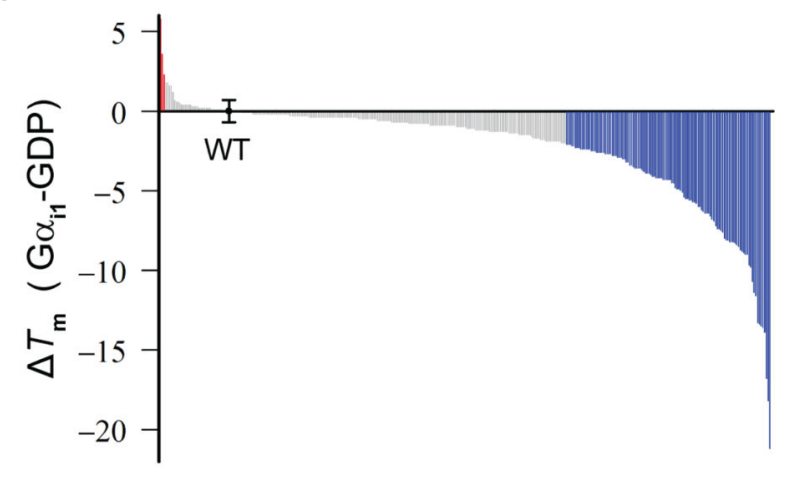

c)

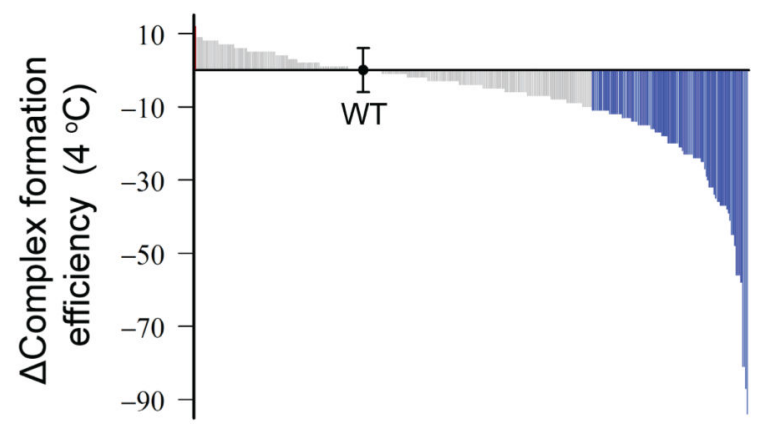

b)

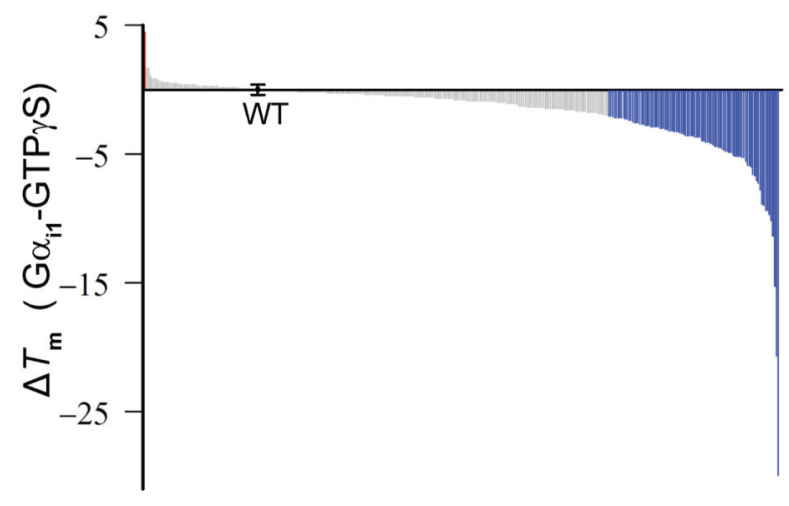

d)

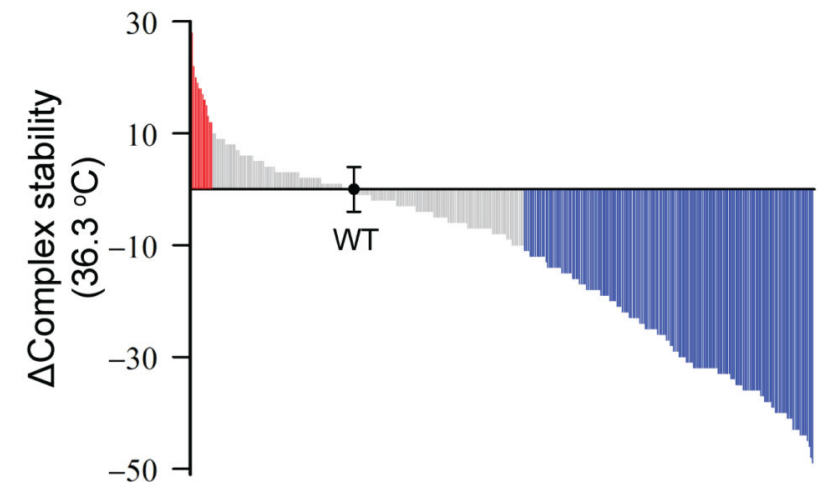

Figure 2. Distribution of effects of $\mathrm{Ga}_{\mathrm{i} 1}$ alanine mutants on the nucleotide-bound and receptorbound states.

a, b, Changes in stability $\left(\Delta T_{\mathrm{m}}\right)$ of $\mathrm{Ga}_{\mathrm{i} 1}$ (Ala)-GDP (w/ $1 \mathrm{mM}$ GDP) (a) and $\Delta T_{\mathrm{m}}$ of $\mathrm{Ga}_{\mathrm{i} 1}$ (Ala)-GTP $\gamma \mathrm{S}(\mathrm{w} / 0.1 \mathrm{mM}$ GTP $\gamma \mathrm{S})\left(\right.$ b). Gray: $-2^{\circ} \mathrm{C}<\Delta T_{\mathrm{m}}<2{ }^{\circ} \mathrm{C}$; blue: $\Delta T_{\mathrm{m}}<-2^{\circ} \mathrm{C}$; red: $2^{\circ} \mathrm{C}<\Delta T_{\mathrm{m}}$. The $\Delta T_{\mathrm{m}}$ of $\mathrm{Ga}_{\mathrm{i} 1}$ (WT)-GDP or -GTP $\gamma \mathrm{S}$ was shown as the black dot. c, Distribution of $\Delta$ complex formation efficiency of Rho*-G $\mathrm{G}_{\mathrm{i}}$ (Ala). Blue: $\Delta$ complex formation efficiency is less than $-10 \%$; gray: between $-10 \%$ and $10 \%$; red: more than $10 \%$. d, Distribution of $\Delta$ complex stability of $\mathrm{Rho}^{*}-\mathrm{G}_{\mathrm{i}}(\mathrm{Ala})$. Blue: $\Delta$ complex stability is less than $-10 \%$; gray: between $-10 \%$ and $10 \%$; red: more than $10 \%$. The definition of $\Delta T_{\mathrm{m}}, \Delta$ complex formation efficiency, and $\Delta$ complex stability are described in the methods section. All data are presented in Supplementary Table 1. As for $\Delta T_{\mathrm{m}}$ of $\mathrm{Ga}_{\mathrm{i} 1}$ (WT)-GDP and $\mathrm{Ga}_{\mathrm{i} 1}$ (Ala)GTP $\gamma \mathrm{S}$, data points represent mean \pm s.d. from 25 and 24 individual experiments, respectively. As for $\Delta$ complex formation efficiency and $\Delta$ complex stability of $\mathrm{Rho}^{*}-\mathrm{G}_{\mathrm{i}}(\mathrm{WT})$, data points represent mean \pm s.d. of 33 and 38 individual experiments, respectively. 
a) $\mathrm{G} \alpha_{i 1}-\mathrm{GDP}$
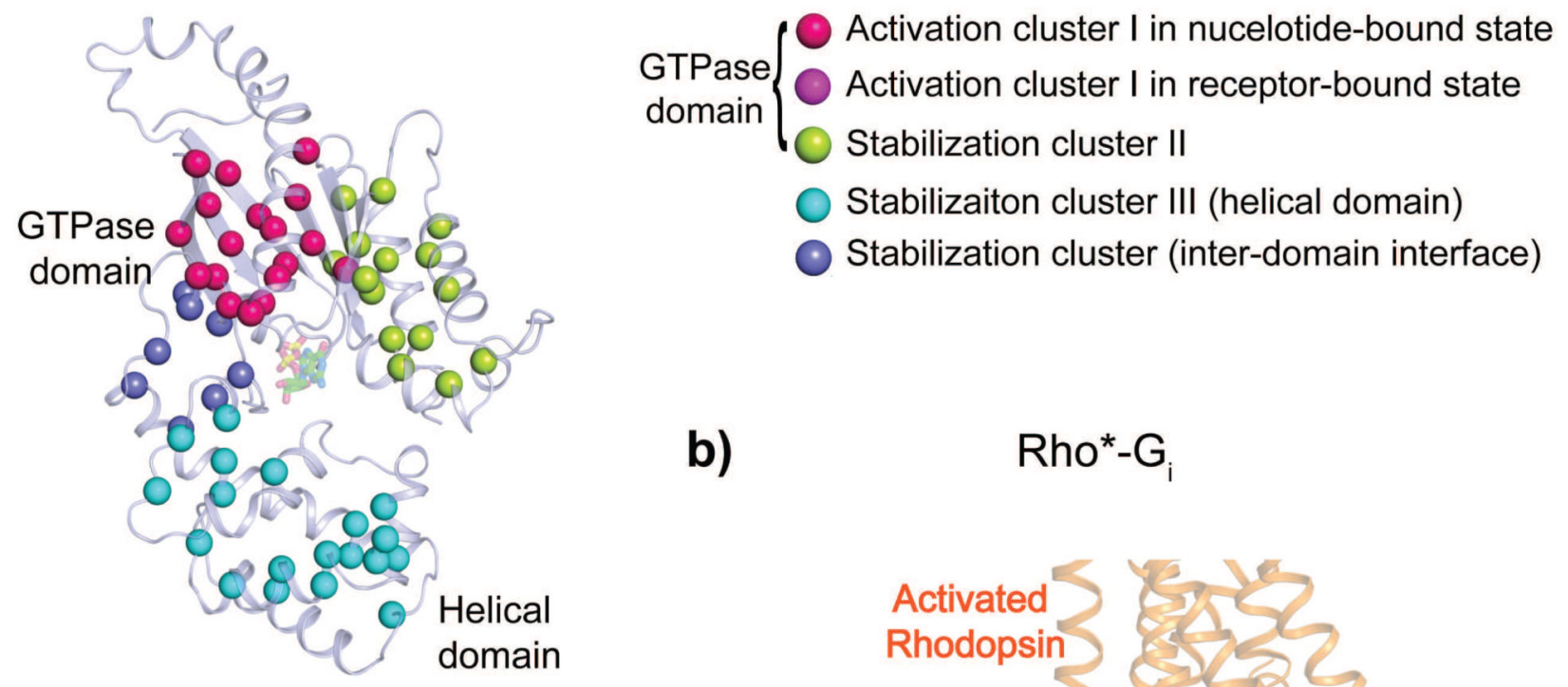

b)

Rho*-G

c)

Go $\alpha_{i 1}-G T P \gamma S$
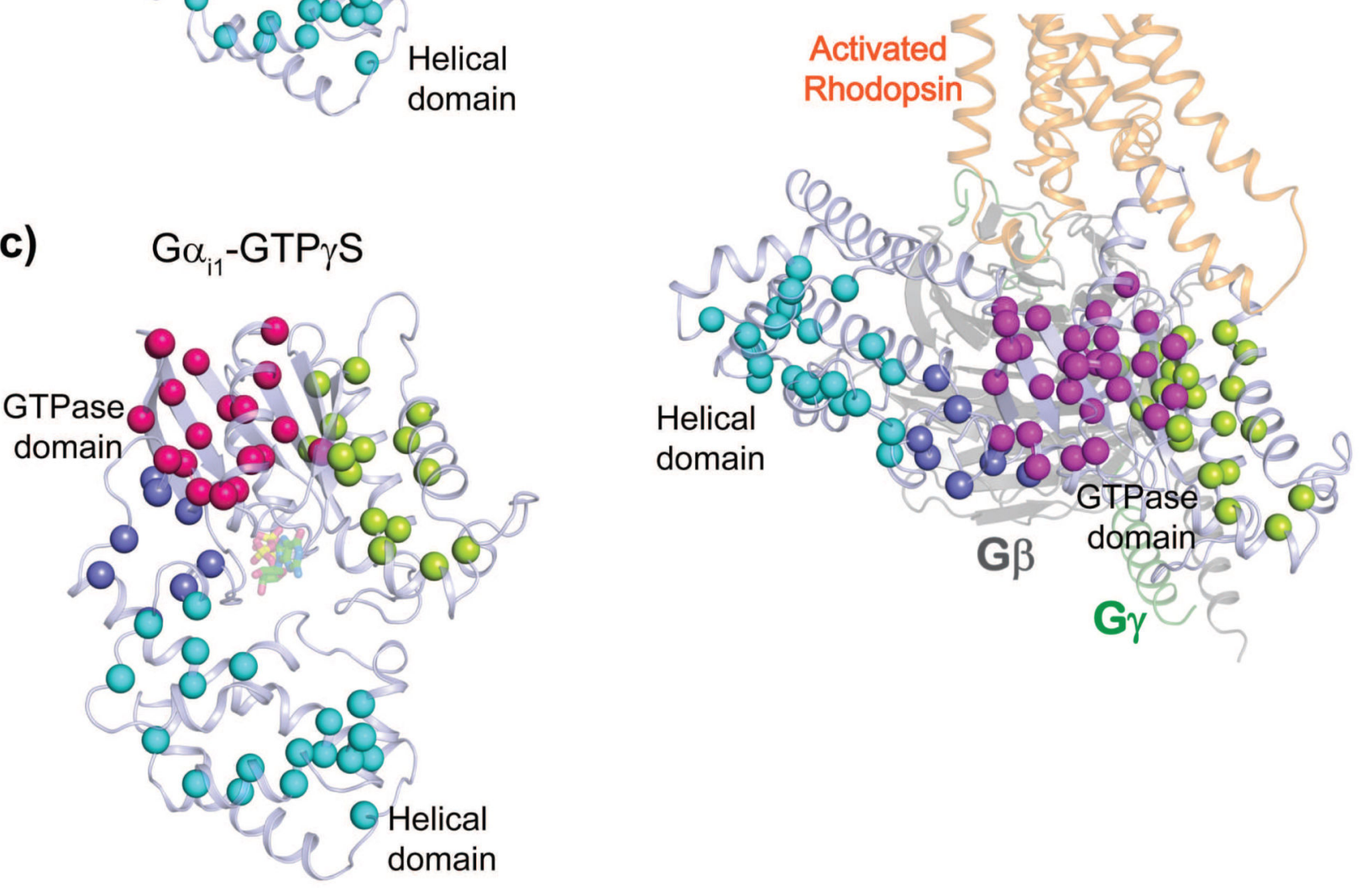

Figure 3. Stabilization clusters in the GTPase, helical domain and the inter-domain interface in the nucleotide- and receptor-bound states.

a-c, Identified stabilization clusters derived from stability effects of $\mathrm{Ga}_{\mathrm{i} 1}$ alanine mutants on GDP- (a), receptor- (b) and GTP $\gamma S$-bound (c) states. The identified activation cluster I and stabilization cluster II in the GTPase domain, the stabilization cluster III in the helical domain, and the stabilization cluster in the inter-domain interface are shown as spheres and mapped to GDP-bound $\mathrm{Ga}_{\mathrm{i} 1}$ state (PDB 1GDD 11) (a), homology model of Rho*-G complex state (b) and GTP $\gamma$ S-bound $\mathrm{Ga}_{\mathrm{i} 1}$ state (PDB 1GIA 10) (c). The stabilization 
cluster II, III and the stabilization cluster in the inter-domain interface are coloured in lemon, cyan and slate blue spheres in all three states, respectively. The activation cluster I is displayed as hot pink spheres in nucleotide-bound state $(\mathbf{a}, \mathbf{c})$, and as magenta spheres in the receptor-bound state (b) to indicate its conformational change upon coupling to the receptor. The relative orientation of the GTPase domain is identical in all states, while the helical domain is displaced in the receptor-bound state. 
a)

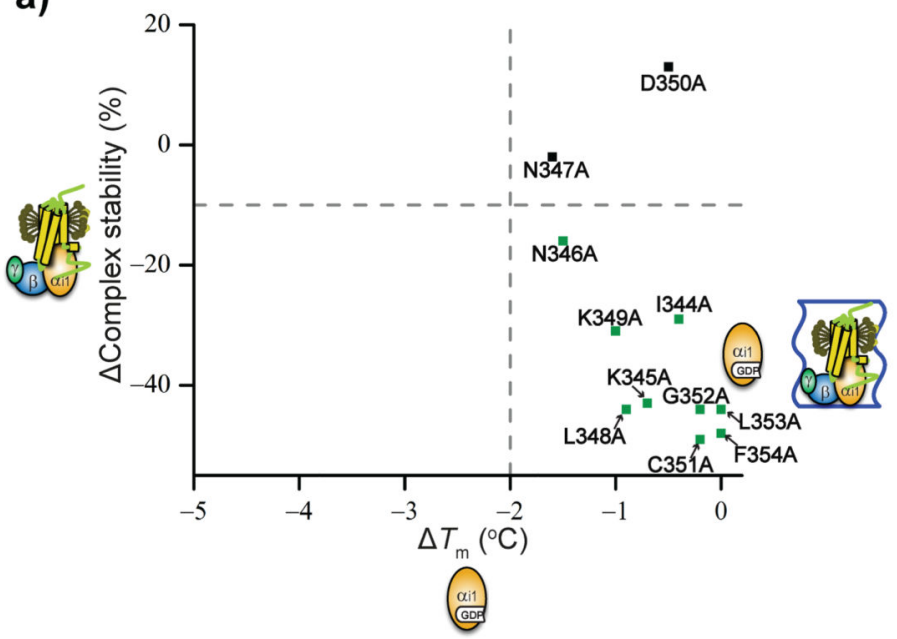

b)

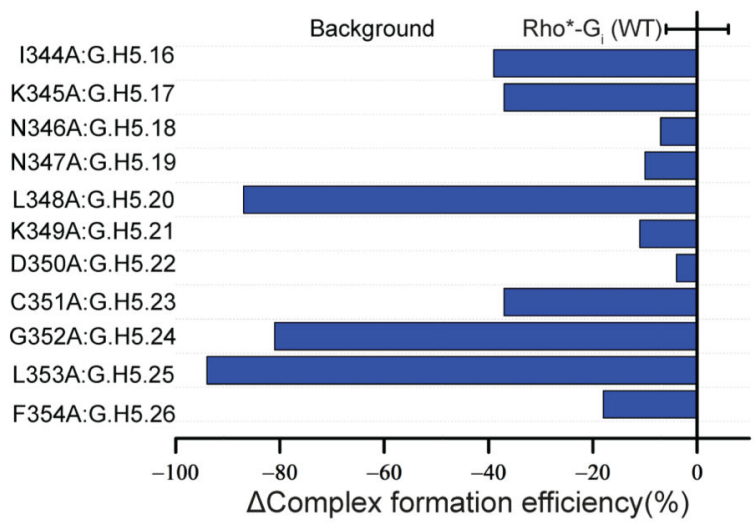

Figure 4. Effect on the nucleotide-bound and receptor-bound states of alanine mutation of the last 11 amino acids of $\mathrm{Ga}_{\mathrm{i1}}$.

a, Effect on the thermal stability of the GDP-bound and receptor-bound states of alanine mutation of the last 11 resides of the $\mathrm{C}$-terminus of $\mathrm{Ga}_{\mathrm{i} 1}$. The CGN of the labelled residues is listed in Supplementary Table 1. b, Effect on Rho*-G $\mathrm{G}_{\mathrm{i}}$ complex formation of alanine mutation of the last 11 resides of the $\mathrm{C}$-terminus of $\mathrm{Ga}_{\mathrm{i} 1}$. The increase in $\Delta$ complex formation efficiency is coloured in red and the decrease is coloured in blue. The definition of $\Delta T_{\mathrm{m}}, \Delta$ complex formation efficiency, and $\Delta$ complex stability are provided in the supplementary methods and the derived numbers are shown in Supplementary Table 1. Data points represent mean \pm s.d. of 33 individual experiments. 
a) GTPase domain (activation cluster I)
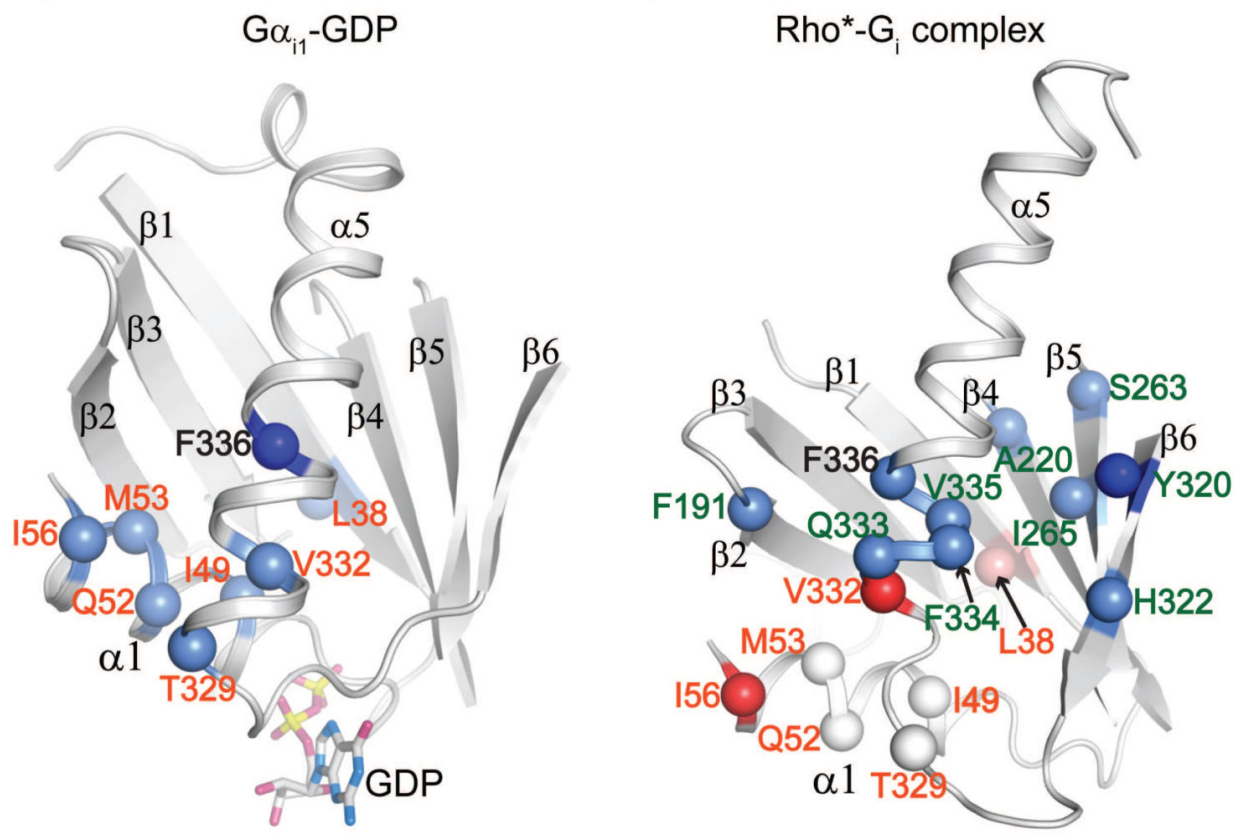

b) GTPase domain (stabilization cluster II)

$$
\mathrm{G} \alpha_{i 1}-\mathrm{GDP}
$$

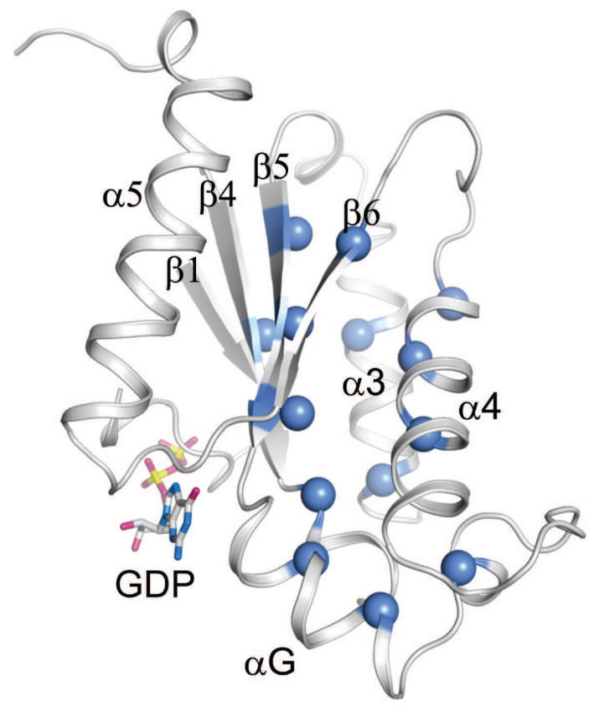

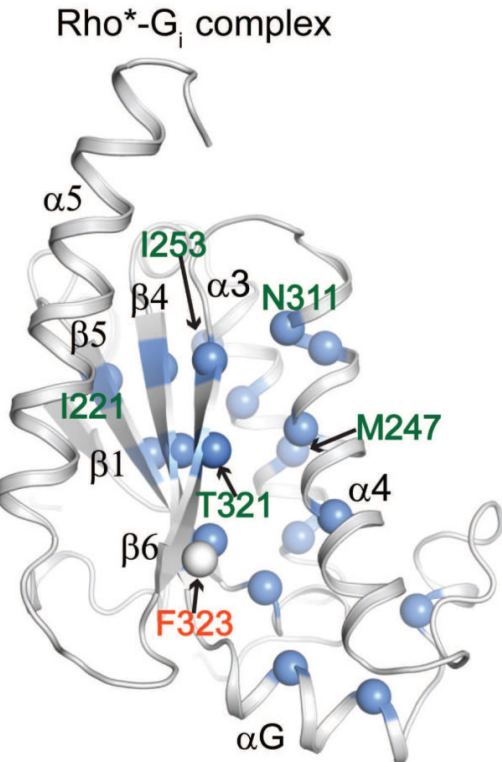

Figure 5. Close-up view of activation cluster I and stabilization cluster II.

a-b, Residues involved in the activation cluster I (a) and the stabilization cluster II (b) of the GTPase domain in GDP-bound and receptor-bound states. The involved residues are shown as spheres in both the GDP-bound and receptor-bound states. Light blue: destabilizing effect by mutation to alanine; white: stability comparable to WT after mutation to alanine; light red: stabilizing effect due to mutation to alanine. Residues labelled in orange: alanine mutations dramatically destabilize the GDP-bound state but not the receptor-bound state; residues labelled in forest green: alanine mutations do not affect the GDP-bound state, but 
significantly destabilize the receptor-bound state; residues without lableing: alanine mutation destablizie both GDP- and receptor-bound state. I56A $\mathrm{A}^{\mathrm{G} H 1.11}$ and V332A $\mathrm{A}^{\text {G.H5.4 }}$ (shown in red) significantly stabilize the complex. The alanine mutation of F336 G.H5.8 completely impairs the stability of the GDP-bound state (shown in deep blue). The alanine mutation of Y $320^{\text {G.S6.2 }}$ severely impairs the complex formation (shown in deep blue). The CGN of the labelled residues is listed in Supplementary Table 1. 
a)

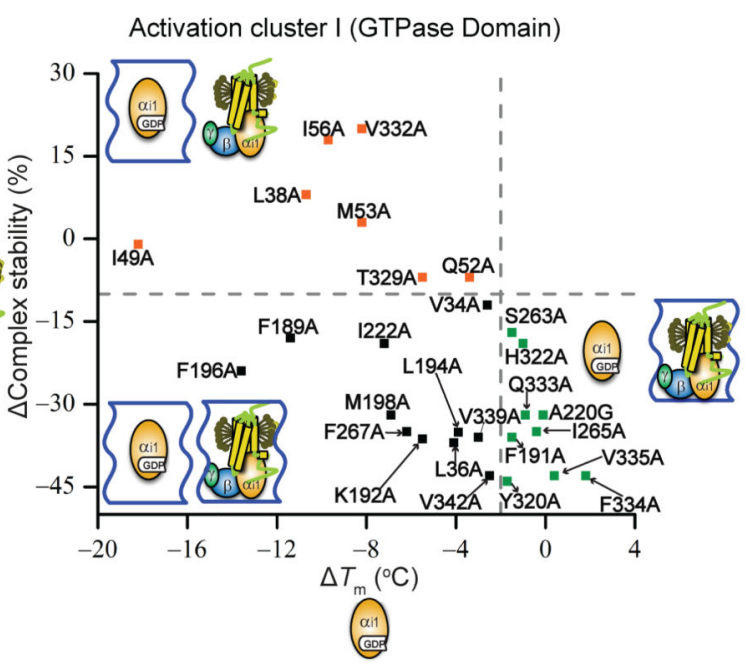

b)

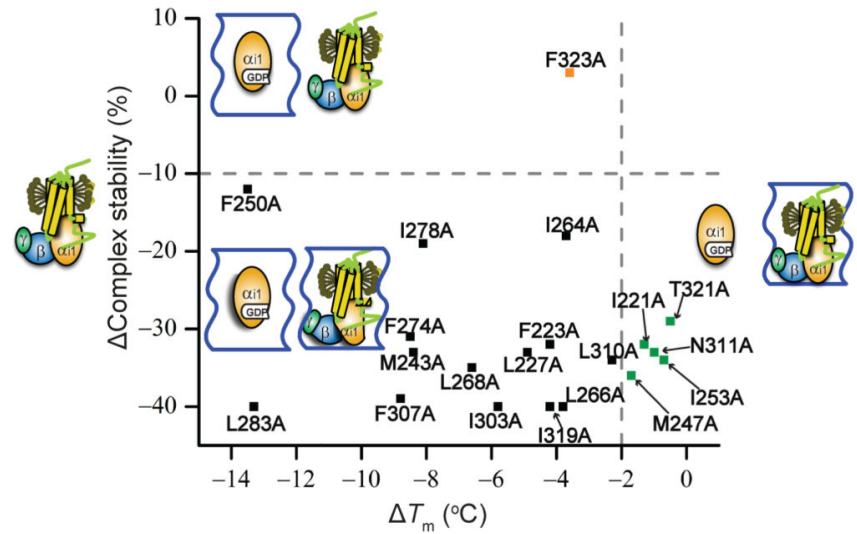

c)

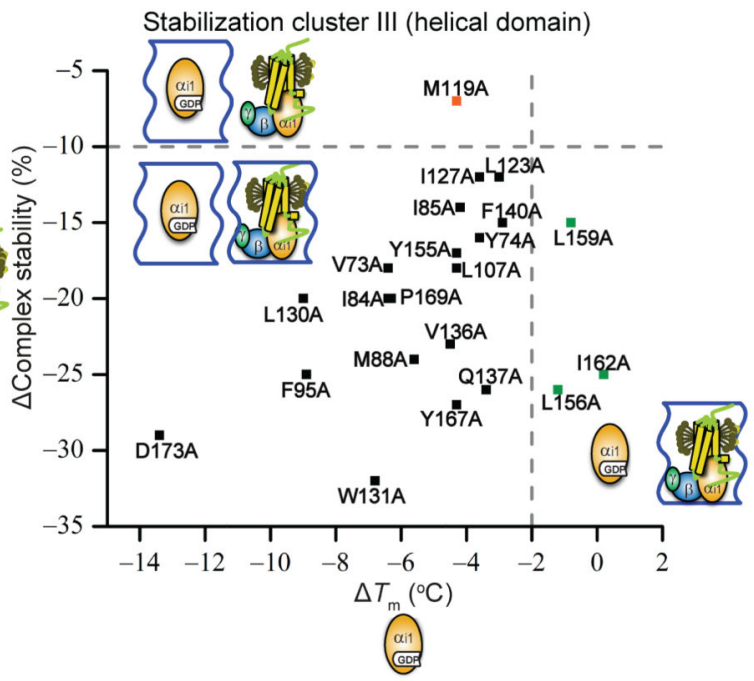

d)

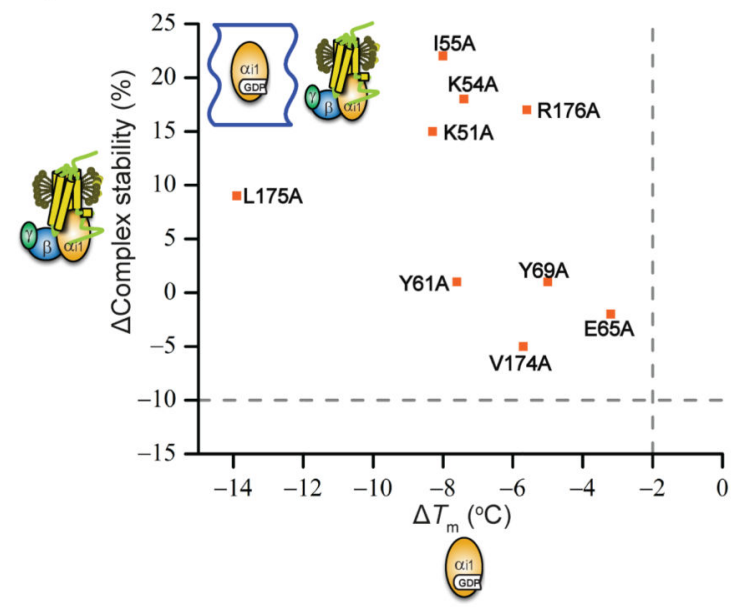

Figure 6. Stability effect of alanine mutation of the residues involved in the activation and stabilization clusters.

a-d, Effect on stability of mutation of the residues involved in the activation cluster I (a), stabilization clusters II (b) and III (c), and the inter-domain interface (d) on the GDP- and receptor-bound states. Orange: mutations that dramatically destabilize the GDP-bound state, but do not affect the stability of receptor-bound state; forest green: mutations that do not destabilize the GDP-bound state, but significantly destabilize the receptor-bound state; black: mutation that destabilize both nucleotide- and receptor-bound states. The alanine mutants represented by the orange and the forest green box correspond to the colour of residue number shown in Fig. 5a-b and Fig. 7a-b. The blue wavy box cartoons represent the nucleotide- or receptor-bound states affected by mutations. 


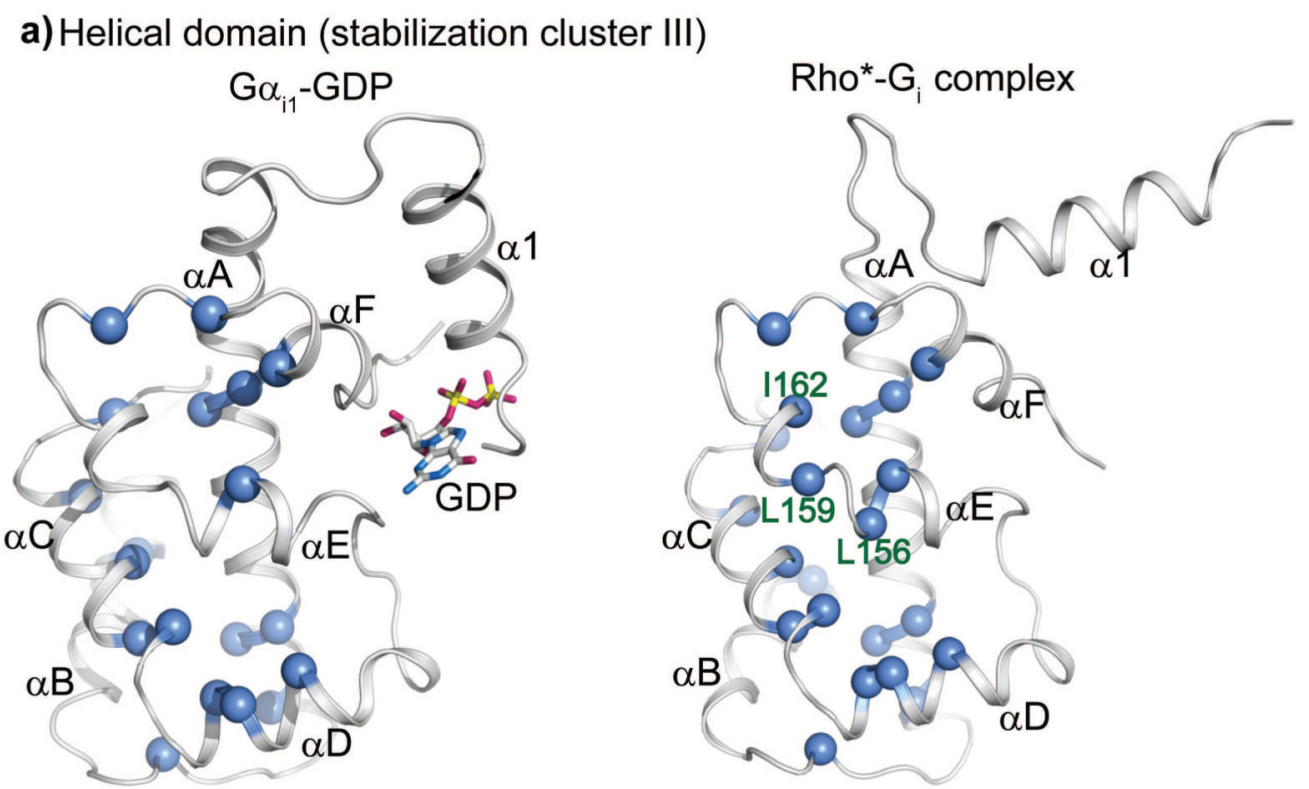

\section{b) Inter-domain interface (stabilization cluster)$$
\mathrm{G}_{\mathrm{i} 1}-\mathrm{GDP} \quad \text { Rho*}-\mathrm{G}_{\mathrm{i}} \text { complex }
$$

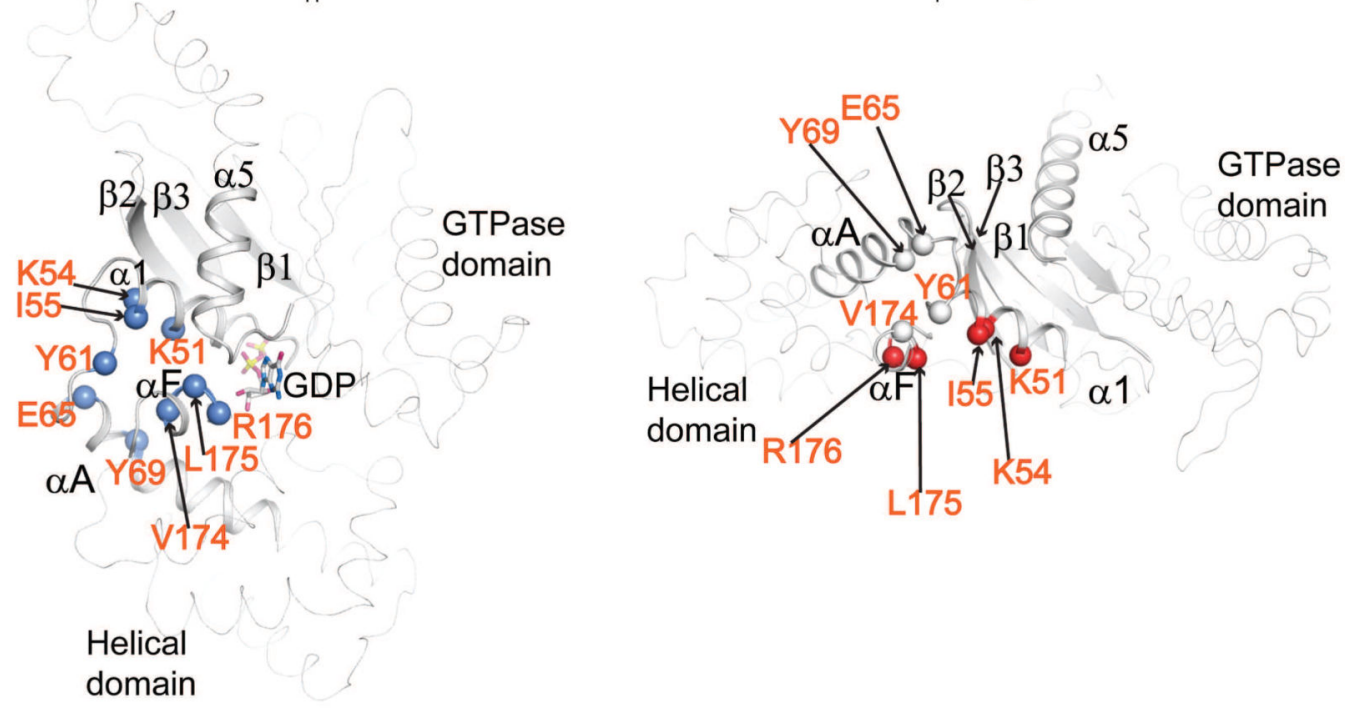

Figure 7. Close-up view of stabilization cluster III and stabilization cluster in the inter-domain interface.

a-b, Reisudes invloved in stabilization clusters in the helical domain (a) and inter-domain interface (b) in GDP-bound and receptor-bound states. The involved residues are shown as spheres in both the GDP-bound and the receptor-bound states. Light blue: destabilising effect by mutation to alanine; white: stability comparable to WT after mutation to alanine; light red: stabilization after mutation to alanine. Residues labelled in orange: alanine mutations dramatically destabilize the GDP-bound state but not the receptor-bound state; 
residues labelled in forest green: alanine mutations do not affect the GDP-bound state, but significantly destabilize the receptor-bound state; residues without lableing: alanine mutation destabilize both GDP- and receptor-bound state. 


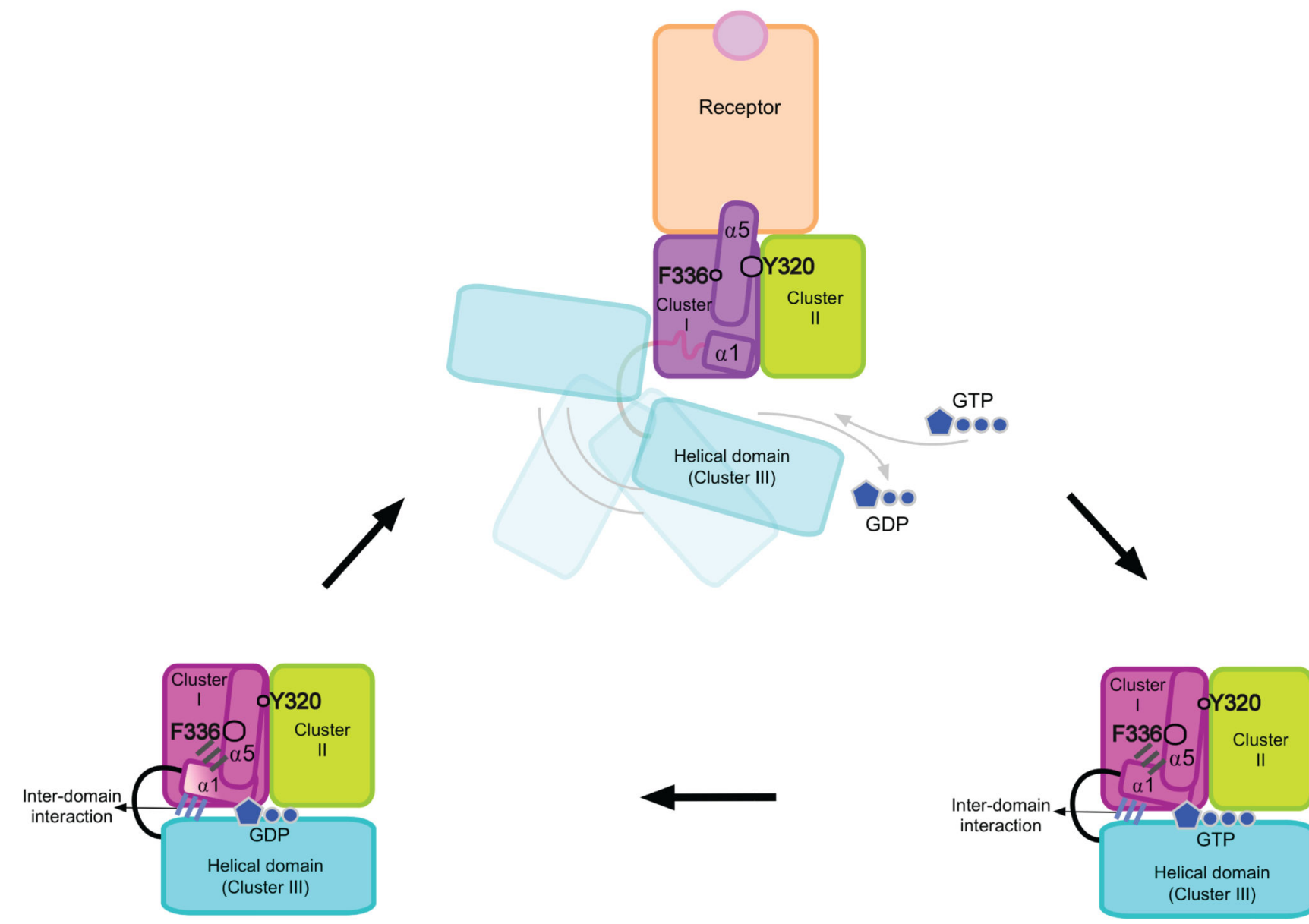

Figure 8. Nucleotide exchange in the $\mathrm{Ga}_{\mathrm{i} 1}$ subunit mediated by the activation and stabilization clusters.

Cluster I is coloured in hot pink in both the GDP- and GTP-bound states, and in magenta in the receptor-bound state. Cluster II and III are coloured in lemon and cyan in the three states, respectively. The inter-domain interaction and the interactions between helices a 1 and a5 are coloured in slate blue and grey, respectively. GDP and GTP are shown in dark blue.

Cluster I consists of helices $a 1$ and a 5 packed against stands $\beta 1-3$ in the nucleotide-bound states. In the receptor-bound state, these interactions are weakened and compensated by new interactions between helix a 5 and stands $\beta 4-6$. The most prominent examples of the residues involved in this rearrangement are $\mathrm{Y} 320^{\mathrm{G} . S 6.2}$, which is crucial for the stabilization of the receptor bound state, and F336 ${ }^{\text {G.H5.8 }}$, important for the stability of the GDP- and GTP-bound states. Destabilization of helix a 1 results in weakening of the inter-domain interface, separation of the helical domain from the GTPase domain and release of GDP. 